\title{
A review of oxygen reduction mechanisms for metal-free carbon-based electrocatalysts
}

\author{
Ruguang Ma ${ }^{1,2}$, Gaoxin Lin ${ }^{1,3}$, Yao Zhou' ${ }^{1}$ Qian Liu' ${ }^{1}$, Tao Zhang $\mathbb{C}^{1}$, Guangcun Shan ${ }^{4}$, Minghui Yang ${ }^{5}$ and Jiacheng Wang ${ }^{1,2}$
}

The sluggish kinetics of Oxygen Reduction Reaction (ORR) at the cathode in proton exchange membrane fuel cells or metal-air batteries requires highly effective and stable electrocatalysts to boost the reaction. The low abundance and high price of Pt-based electrocatalysts hamper the widespread application of proton exchange membrane fuel cells and metal-air batteries. As promising alternatives, metal-free carbon materials, especially upon doping heteroatoms or creating defects demonstrated excellent ORR activity, which is as efficient as or even superior to commercial platinum on carbon. Significant progress on the development of advanced carbon materials as highly stable and durable catalysts has been achieved, but the catalytic mechanisms of these materials still remain undistinguished. In present review, we summarized the up-to-date progress in the studies of carbon materials, and emphasized on the combination of experiment and theory to clarify the underlying mechanisms of these materials. At last, we proposed the perspectives on the proper strategies of elucidating the mechanisms of carbon materials as electrocatalysts towards ORR.

npj Computational Materials (2019)5:78; https://doi.org/10.1038/s41524-019-0210-3

\section{INTRODUCTION}

Advanced technique for sustainable energy storage and conversion has extensively attracted considerable attention in academia and industry, due to the accelerated depletion of fossil fuels and accompanied environmental pollution. ${ }^{1}$ Proton exchange membrane fuel cells (PEMFCs) and rechargeable metal-air batteries (MABs) are next-generation energy devices for clean power generation. ${ }^{2,3}$ During the discharging process in PEMFCs or MABs, the oxygen reduction reaction (ORR) occurs at the cathode, where $\mathrm{O}_{2}$ molecules are reduced by electrons. But it is very difficult to electrochemically break the $\mathrm{O}=\mathrm{O}$ bond, which possesses an exceptionally strong bond energy of $498 \mathrm{~kJ} \mathrm{~mol}^{-1}$. The assistance of electrocatalysts for the bond activation and cleavage is necessary to lower the energy barrier. The ORR at the cathode is more than six orders slower than hydrogen oxidation at the anode in aqueous solutions in the PEMFCs, arising from the varied adsorption/desorption and reaction pathways, which involve different O-containing intermediates (e.g. $\mathrm{OOH}^{*}, \mathrm{O}^{*}$, and $\left.\mathrm{OH}^{*}\right)^{5}$ As a result, the usage of catalyst for the cathode is usually ten times more than that for the anode. ${ }^{6}$ Industrially, the commercial electrocatalysts for the ORR are precious Pt-based nanomaterials, which accounts for $36-56 \%$ of the cost of the PEMFCs. ${ }^{7,8}$ Besides the high cost arising from the limited availability, these Pt-based electrocatalysts are usually susceptible to fuel crossover and suffer from poor stability, thus tremendously limiting the massive applications. Therefore, it is of paramount importance to develop cost-efficient, highly active and stable ORR electrocatalysts to substitute Pt-based electrodes for large-scale applications of PEMFCs or MABs.
Carbon materials are a new class of catalyst firstly reported by Dai's group in 2009, ${ }^{9}$ which holds the promise to replace Pt to efficiently catalyze the ORR in fuel cells, owing to their large surface area, good conductivity, tunable morphology, facile preparation, and economic viability. ${ }^{10}$ It was found that, in the ORR process, nano-forests of $\mathrm{N}$-doped carbon nanotubes performed better than commercially available $\mathrm{Pt} / \mathrm{C}$ electrodes according to catalytic efficiency and long-term durability in alkaline fuel cells. ${ }^{9}$ Subsequently, $\mathrm{N}$-doped graphene and graphitic flakes were extensively synthesized and most reported samples can efficiently electrocatalyze the ORR via a four-electron pathway in alkaline fuel cells, which possessed better catalytic activity, stability, and tolerance to methanol crossover effect than $\mathrm{Pt} / \mathrm{C}$. $^{11-}$

15 Following this pioneering work, various heteroatom-doped carbon materials were investigated, such as B-doped CNTs or graphene (BG), ${ }^{16,17}$ sulfur-doped graphene (SG), ${ }^{18-21}$ phosphorous-doped graphite layers, ${ }^{22}$ iodine-doped graphene ${ }^{23}$, and edge-halogenated $(\mathrm{Cl}, \mathrm{Br}$ or I) graphene nanoplatelets (GnPs). ${ }^{24}$ For example, Antonietti's group developed mesoporous $\mathrm{N}$-doped carbon materials with high surface area of $1500 \mathrm{~m}^{2} \mathrm{~g}^{-1}$ by carbonization of nucleobases dissolved in an all-organic ionic liquid. ${ }^{25}$ Moreover, binary or ternary doping of different heteroatoms into carbon materials were performed and investigated, such as B, N co-doped VA-CNTs or graphene, ${ }^{26-28} \mathrm{~N}$, S-doped graphene (NSG), ${ }^{29-31} \mathrm{~N}$, P-doped graphene (NPG), ${ }^{32,33} \mathrm{~N}, \mathrm{~B}$, P-doped carbon. ${ }^{34}$ In this regard, Strasser's group have ever reported a general strategy to synthesize a series of heteroatom-doped carbon materials, such as N-doped, N-S, N-P, and N-B co-doped carbon hybrids, by employing nitrile-functionalized ionic

\footnotetext{
${ }^{1}$ State Key Laboratory of High Performance Ceramics and Superfine Microstructure, Shanghai Institute of Ceramics, Chinese Academy of Sciences, 1295 Dingxi Road, 200050 Shanghai, China; ${ }^{2}$ Center of Materials Science and Optoelectronics Engineering, University of Chinese Academy of Sciences, 100049 Beijing, China; ${ }^{3}$ University of Chinese

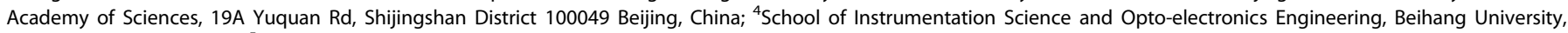
100191 Beijing, China and ${ }^{5}$ Ningbo Institute of Materials Technology and Engineering, Chinese Academy of Sciences, 315201 Ningbo, China

Correspondence: Guangcun Shan (gcshan@buaa.edu.cn) or Jiacheng Wang (jiacheng.wang@mail.sic.ac.cn)

These authors contributed equally: Ruguang Ma, Gaoxin Lin
}

Received: 19 August 2018 Accepted: 26 June 2019

Published online: 19 July 2019 
(a)
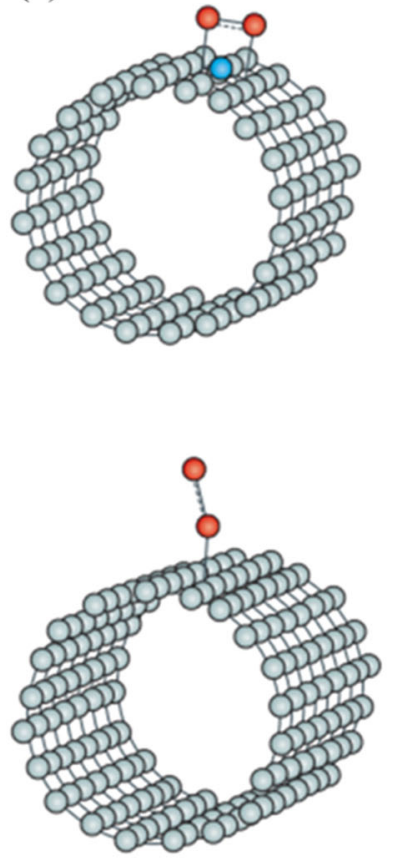

(b)

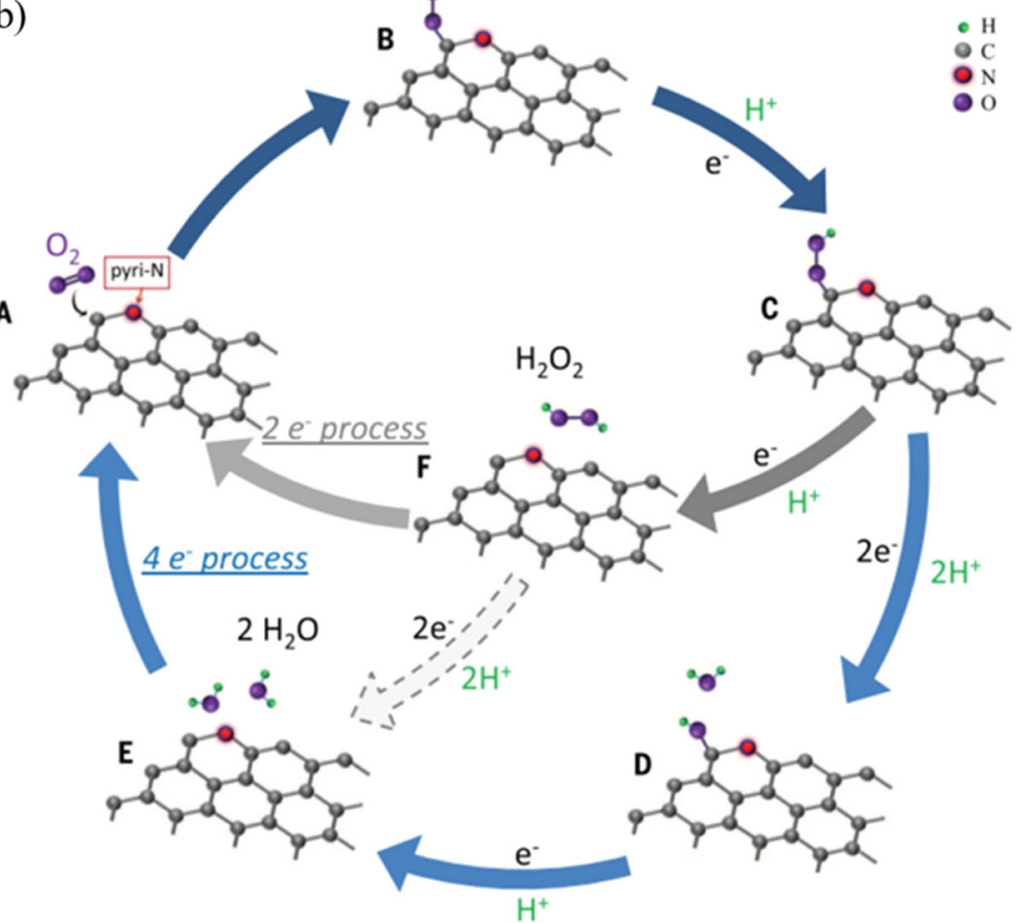

Fig. 1 a Schematic illustrations of two possible modes of $\mathrm{O}_{2}$ molecule adsorption at N-doped CNT (up panel) and a non-doped CNT (down panel) (reproduced with permission from ref. ${ }^{43}$, Copyright ${ }^{\circ}$ Springer Nature 2011). b Schematic pathway for ORR on N-doped carbon materials (reproduced with permission from ref. ${ }^{\prime 4}$, Copyright $^{\circledR} 2016$ AAAS)

precursors. ${ }^{35}$ The publications containing both "carbon materials" and "oxygen reduction reaction" keywords increase rapidly every year in the last decade, demonstrating that carbon materials used as catalysts kept on being a hot topic in the electrocatalytic ORR.

The improved catalytic performance for $\mathrm{N}$-doped or B-doped carbon materials was given credits to the redistribution of charge density of adjacent $C$ atoms, due to the large electronegativity differences between N/B atoms $\left(X_{N}=3.04, X_{B}=2.04\right.$ on the Pauling scale) and carbon atoms $\left(X_{C}=2.55\right)$, thus changing the $\mathrm{O}_{2}$ molecules chemisorption mode and readily facilitating the attraction of electrons from the anode. ${ }^{16,36} \mathrm{~S}$ atoms have the comparable electronegativity $\left(X_{s}=2.58\right)$ to that of $C$ atom, so the redistribution of atomic charge density is relatively much smaller. But the S-doped graphene also demonstrates superior electrocatalytic activity to the counterpart without doping. ${ }^{18,37}$ The electronic spin density of carbon atoms, especially those edge-site carbon atoms, was regarded as the dominant factor to enhance the catalytic activity of S-doped graphene. ${ }^{19,38}$ For dual-doped carbon materials, the origin of enhanced electrocatalytic activity was also ascribed to the delocalization of spin or charge density. ${ }^{27}$ Meanwhile, additional doping of boron or phosphorus in nitrogendoped graphene could lower the energy gap of $\mathrm{N}$-doped graphene materials, which is also favorable to the ORR activity. ${ }^{32}$ Abundant intrinsic defects either in the basal plane or at the edges have also significant contribution to the ORR activity of carbon materials, because they could also give rise to damage of the integrity of $\pi$ conjugation. ${ }^{39,40}$

Despite extensive studies and productive achievements over decades, the sluggish kinetics and recondite mechanisms of the ORR have not been well understood because of the difficulty to exactly identify the active sites, the complicated transfer process from protons/electrons to oxygen molecule, as well as the scissoring of $\mathrm{O}=\mathrm{O}$ bonds. It is still challengeable to exactly manipulate the location and content of heteroatoms in the carbon basal plane and to build a well-defined relationship between the doped configuration and electrocatalytic activity. Herein, we clarify the situation by critically analyzing the relevant literature and briefly summarize the recent progress on the electrocatalytic mechanisms on carbon nanomaterials, along with the perspectives on the proper design of carbon materials as electrocatalysts for highly efficient ORR.

\section{FUNDAMENTALS OF ORR}

\section{Reaction pathways}

In aqueous electrolyte, the reaction process of oxygen reduction at the cathode of fuel cells or MABs includes the following steps: (a) $\mathrm{O}_{2}$ molecules diffusion and adsorption at the surface of electrocatalysts, (b) electron transport from anode to adsorbed $\mathrm{O}_{2}$ molecules, (c) weakening and splitting of $\mathrm{O}=\mathrm{O}$ bindings, and (d) removing the produced $\mathrm{OH}^{-}$ions to solutions. ${ }^{41,42}$ The ORR proceeds through either a highly efficient four-electron pathway in one step or a sluggish two-electron pathway in two steps to complete the reduction of $\mathrm{O}_{2}$ molecules to $\mathrm{OH}^{-}$ions. There are usually two adsorption types on the surface of carbon materials based on the computational charge density distribution as illustrated in Fig. 1.,43 One is the bidentate $\mathrm{O}_{2}$ molecule adsorption (the Yeager model, two oxygen atoms coordinating with the metal, Fig. 1 up panel), and the other is the end-on $\mathrm{O}_{2}$ molecule adsorption (the Pauling model, one oxygen atom coordinating perpendicularly to the surface, Fig. 1 down panel). For a direct four-electron pathway, the reactions in alkaline (Eq. 1) or acidic (Eq. 2) electrolyte are as follows:

$$
\begin{aligned}
& \mathrm{O}_{2}+2 \mathrm{H}_{2} \mathrm{O}+4 \mathrm{e}^{-} \rightarrow 4 \mathrm{OH}^{-}(0.401 \mathrm{~V} v \text { s. SHE }) \\
& \mathrm{O}_{2}+4 \mathrm{H}^{+}+4 \mathrm{e}^{-} \rightarrow 2 \mathrm{H}_{2} \mathrm{O}(1.229 \mathrm{~V} \text { vs. SHE })
\end{aligned}
$$

where, SHE stands for standard hydrogen electrode.

For indirect two-electron two steps, after the first two-electron oxygen reduction in alkaline solution (Eq. 3a), either a further twoelectron reduction of $\mathrm{H}_{2} \mathrm{O}_{2}$ (Eq. 3b) or the chemical 
disproportionation of $\mathrm{H}_{2} \mathrm{O}_{2}$ (Eq. 3b') happened:

$\mathrm{O}_{2}+\mathrm{H}_{2} \mathrm{O}+2 \mathrm{e}^{-} \rightarrow \mathrm{HO}_{2}^{-}(-0.076$ V v. SHE $)$

$\mathrm{HO}_{2}^{-}+\mathrm{H}_{2} \mathrm{O}+2 \mathrm{e}^{-} \rightarrow 3 \mathrm{HO}^{-}(0.878 \mathrm{~V}$ vs. SHE $)$

$2 \mathrm{HO}_{2}^{-} \rightarrow 2 \mathrm{HO}^{-}+\mathrm{O}_{2}$

In acidic solution, the two-step 2e pathway includes the following steps (Eq. 4a and $4 b$ ):

$\mathrm{O}_{2}+2 \mathrm{H}^{+}+2 \mathrm{e}^{-} \rightarrow 2 \mathrm{H}_{2} \mathrm{O}_{2}(0.695 \mathrm{~V}$ vs. SHE $)$

$\mathrm{H}_{2} \mathrm{O}_{2}+2 \mathrm{H}^{+}+2 \mathrm{e}^{-} \rightarrow 2 \mathrm{H}_{2} \mathrm{O}(1.776 \mathrm{~V}$ vs. SHE $)$

The latest research results about the reaction mechanism on $\mathrm{N}$ doped carbon materials demonstrated that carbon atoms next to pyridinic $\mathrm{N}$ show Lewis basicity and the oxygen molecule is first adsorbed at such carbon atoms followed by protonation of the adsorbed $\mathrm{O}_{2}$ as shown in Fig. $1 \mathrm{~b} .{ }^{44}$ Then two pathways possibly take place: one is the four-electron pathway taking place at a single site $(A \rightarrow B \rightarrow C \rightarrow D \rightarrow E \rightarrow A)$, and the other is the two-step two-electron pathway $(A \rightarrow B \rightarrow C \rightarrow F \rightarrow E \rightarrow A)$, which does not always occur at a single site.

In the nonstandard conditions, the Nernst equation is usually used to quantitatively describe the oxygen reduction potential:

$$
\mathrm{E}=\mathrm{E}^{0}-\frac{\mathrm{RT}}{\mathrm{nF}} \ln \frac{\mathrm{a}_{\mathrm{O}_{\mathrm{x}}}}{\mathrm{a}_{\text {Red }}}
$$

where $\mathrm{E}^{0}$ is the standard reduction potential of $\mathrm{O}_{2}$ to $\mathrm{OH}^{-}$ions at $298 \mathrm{~K}, \mathrm{~F}$ represents the Faraday constant $\left(\mathrm{F}=96485 \mathrm{C} \mathrm{mol}^{-1}\right), \mathrm{T}$ stands for the temperature in Kelvin, $R$ represents the gas constant, $a$ is the activity of the oxidized and reduced species, and $n$ is the electron transferred number. At $298 \mathrm{~K}$ and $1.0 \mathrm{~atm}$ of $\mathrm{O}_{2}$ pressure, $\mathrm{E}^{0}$ related to the $\mathrm{RHE}$ (reversible hydrogen electrode) can be converted from SHE by Eq. (6):

$\mathrm{E}_{\mathrm{RHE}}=\mathrm{E}_{\mathrm{SHE}}+0.059 \times \mathrm{pH}$

\section{Theoretical descriptors}

A universal design principle for electrocatalysts has been desired to provide experimental guidance and mechanism explanation. Early in 2004, Nørskov and co-workers investigated the reaction free energy $(\Delta G)$ of different reaction intermediates during the electrochemical processes of ORR based on electronic structure calculations by employing density functional theory (DFT) in conjunction with SHE model. ${ }^{45}$ With the explosive development of electrocatalysts, such reaction-free energy was extensively used as a descriptor to evaluate the catalytic activity or selectivity of emerging electrocatalysts. Within the electrochemical framework developed by Nørskov et al., two possible ORR mechanisms are proposed: associative mechanism involving a $\mathrm{HOO}^{*}$ species and a direct $\mathrm{O}_{2}$ dissociation mechanism in an acid or alkaline electrolyte. In an acid environment, the associative mechanism goes through the following elementary steps:

$$
\begin{aligned}
& \mathrm{O}_{2}(\mathrm{~g})+* \rightarrow \mathrm{O}_{2}^{*} \\
& \mathrm{O}_{2}^{*}+\mathrm{H}^{+}+\mathrm{e}^{-} \rightarrow \mathrm{HOO}^{*} \\
& \mathrm{HOO}^{*}+\mathrm{H}^{+}+\mathrm{e}^{-} \rightarrow \mathrm{O}^{*}+\mathrm{H}_{2} \mathrm{O}(\mathrm{I}) \\
& \mathrm{O}^{*}+\mathrm{H}^{+}+\mathrm{e}^{-} \rightarrow \mathrm{HO}^{*} \\
& \mathrm{HO}^{*}+\mathrm{H}^{+}+\mathrm{e}^{-} \rightarrow \mathrm{H}_{2} \mathrm{O}(\mathrm{I})+*
\end{aligned}
$$

where ${ }^{*}$ stands for an active site on the surface of electrocatalyst, (I) and (g) refer to liquid and gas phases, respectively, and $\mathrm{O}^{*}, \mathrm{OH}^{*}$ and $\mathrm{HOO}^{*}$ are the adsorbed intermediates.
In an alkaline electrolyte, $\mathrm{H}_{2} \mathrm{O}$ rather than $\mathrm{H}_{3} \mathrm{O}^{+}$may act as the proton donor, and the corresponding steps in the ORR proceed as follows:

$$
\begin{aligned}
& \mathrm{O}_{2}(\mathrm{~g})+* \rightarrow \mathrm{O}_{2}^{*} \\
& \mathrm{O}_{2}^{*}+\mathrm{H}_{2} \mathrm{O}(\mathrm{I})+\mathrm{e}^{-} \rightarrow \mathrm{HOO}^{*}+\mathrm{OH}^{-} \\
& \mathrm{HOO}^{*}+\mathrm{e}^{-} \rightarrow \mathrm{O}^{*}+\mathrm{OH}^{-} \\
& \mathrm{O}^{*}+\mathrm{H}_{2} \mathrm{O}(\mathrm{I})+\mathrm{e}^{-} \rightarrow \mathrm{HO}^{*}+\mathrm{OH}^{-} \\
& \mathrm{HO}^{*}+\mathrm{e}^{-} \rightarrow \mathrm{OH}^{-}+*
\end{aligned}
$$

The mechanism via direct $\mathrm{O}_{2}$ dissociation of oxygen atoms starts with the following elementary step:

$\mathrm{O}_{2}(\mathrm{~g})+*+* \rightarrow \mathrm{O}^{*}+\mathrm{O}^{*}$

followed by steps (10) and (11) in acidic environment or (15) and (16) in alkaline solution.

The overpotential of ORR can be determined by examining the reaction free energy of the different elementary steps, based on the assumption that there are no extra barriers from, e.g., adsorption/dissociation of $\mathrm{O}_{2}$ or proton/electron transfer reaction. This is because the transfer of a solvated proton to adsorbed $\mathrm{OH}^{-}$ during the proton-transfer steps shows a negligible barrier, suggesting that the proton transfer in energy is downhill, and most reported models neglect the effect of the electric field in the double layer, so the calculated free energy of intermediates shows no difference in acidic and alkaline environment at fixed potential on the RHE scale. ${ }^{46}$ These approximations may result in slight overestimation of activity for a given proton-transfer elementary step, but can still qualitatively represent the relative energetic ordering. The adsorption free energy $\left(\Delta G_{a d s}\right)$ of reactant and product molecules adsorbed on catalyst surface can be obtained by the following equation, ${ }^{47}$

$\Delta \mathrm{G}_{\mathrm{ads}}=\Delta \mathrm{E}_{\mathrm{ads}}+\Delta \mathrm{E}_{\mathrm{ZPE}}-\mathrm{T} \Delta \mathrm{S}$

where $\Delta \mathrm{E}_{\mathrm{ads}}$ is the binding energy of adsorption, $\Delta \mathrm{E}_{\mathrm{ZPE}}$ is zeropoint energy of each adsorbate or free molecules calculated by the vibrational frequency of each adsorbed species, $T$ is the temperature, and $\Delta S$ is the entropy change. Entropy values of gaseous molecules can be taken from the standard tables in the Physical Chemistry text book, while the entropies of adsorbate and adsorption site are negligible. To be specific, the adsorption energy of the intermediates $\left(\mathrm{O}^{*}, \mathrm{OH}^{*}\right.$, and $\left.\mathrm{OOH}^{*}\right)$ can be expressed as Eqs. (19)-(21):

$$
\begin{aligned}
\Delta \mathrm{G}_{\mathrm{O}^{*}}= & \Delta \mathrm{G}\left(\mathrm{H}_{2} \mathrm{O}(\mathrm{g})+* \rightarrow \mathrm{O}^{*}+\mathrm{H}_{2}(\mathrm{~g})\right) \\
= & \left(\mathrm{E}_{\mathrm{O}^{*}}+\mathrm{E}_{\mathrm{H}_{2}}-\mathrm{E}_{\mathrm{H}_{2} \mathrm{O}}-\mathrm{E}_{*}\right)+\left(\mathrm{E}_{\mathrm{ZPE}\left(\mathrm{O}^{*}\right)}+\mathrm{E}_{\mathrm{ZPE}\left(\mathrm{H}_{2}\right)}-\mathrm{E}_{\mathrm{ZPE}\left(\mathrm{H}_{2} \mathrm{O}\right)}-\mathrm{E}_{\mathrm{ZPE}(*)}\right) \\
& -\mathrm{T} \times\left(\mathrm{S}_{\mathrm{O}^{*}}+\mathrm{S}_{\mathrm{H}_{2}}-\mathrm{S}_{\mathrm{H}_{2} \mathrm{O}}-\mathrm{S}_{*}\right) \\
\Delta \mathrm{OH}^{*}= & \Delta \mathrm{G}\left(\mathrm{H}_{2} \mathrm{O}(\mathrm{g})+* \rightarrow \mathrm{OH}^{*}+1 / 2 \mathrm{H}_{2}(\mathrm{~g})\right) \\
= & \left(\mathrm{E}_{\mathrm{OH}^{*}}+1 / 2 \mathrm{E}_{\mathrm{H}_{2}}-\mathrm{E}_{\mathrm{H}_{2} \mathrm{O}}-\mathrm{E}_{*}\right)+\left(\mathrm{E}_{\mathrm{ZPE}\left(\mathrm{OH}^{*}\right)}+1 / 2 \mathrm{E}_{\mathrm{ZPE}\left(\mathrm{H}_{2}\right)}-\mathrm{E}_{\mathrm{ZPE}\left(\mathrm{H}_{2} \mathrm{O}\right)}-\mathrm{E}_{\mathrm{ZPE}(*)}\right) \\
& \quad-\mathrm{T} \times\left(\mathrm{S}_{\mathrm{OH}^{*}}+1 / 2 \mathrm{~S}_{\mathrm{H}_{2}}-\mathrm{S}_{\mathrm{H}_{2} \mathrm{O}}-\mathrm{S}_{*}\right)
\end{aligned}
$$

$$
\begin{aligned}
\Delta \mathrm{G}_{\mathrm{OOH}}= & \Delta \mathrm{G}\left(2 \mathrm{H}_{2} \mathrm{O}(\mathrm{g})+* \rightarrow \mathrm{OOH}^{*}+3 / 2 \mathrm{H}_{2}(\mathrm{~g})\right) \\
= & \left.\left(\mathrm{E}_{\mathrm{OOH}}+3 / 2 \mathrm{E}_{\mathrm{H}_{2}}-2 \mathrm{E}_{\mathrm{H}_{2} \mathrm{O}}-\mathrm{E}_{*}\right)+\left(\mathrm{E}_{\mathrm{ZPE}(\mathrm{OH}}\right)+3 / 2 \mathrm{E}_{\mathrm{ZPE}\left(\mathrm{H}_{2}\right)}-2 \mathrm{E}_{\mathrm{ZPE}\left(\mathrm{H}_{2} \mathrm{O}\right)}-\mathrm{E}_{\mathrm{ZPE}(*)}\right) \\
& -\mathrm{T} \times\left(\mathrm{S}_{\mathrm{OOH}^{*}}+3 / 2 \mathrm{~S}_{\mathrm{H}_{2}}-2 \mathrm{~S}_{\mathrm{H}_{2} \mathrm{O}}-\mathrm{S}_{*}\right)
\end{aligned}
$$

For each elementary step, the reaction free energy $\Delta G$ is defined as the difference between free energies of the initial and final states and is given by the expression:

$$
\Delta \mathrm{G}=\Delta \mathrm{E}+\Delta \mathrm{E}_{\mathrm{ZPE}}-\mathrm{T} \Delta \mathrm{S}+\Delta \mathrm{G}_{\mathrm{U}}+\Delta \mathrm{G}_{\mathrm{pH}}
$$

$\Delta \mathrm{G}=-\mathrm{neU}$ 
where $\mathrm{U}$ is the electrode applied potential, and e is the transferred charge and $\mathrm{n}$ is the number of proton-electron transferred pairs. The ORR was analyzed using intermediate species associated with one electron transfer at a time, which is energetically more favorable than the simultaneous transfer of more than one electron. $\Delta \mathrm{G}_{\mathrm{pH}}$ is the correction of the $\mathrm{H}^{+}$free energy by the concentration dependence of the entropy:

$\Delta \mathrm{G}_{\mathrm{pH}}=\mathrm{k}_{\mathrm{B}} \operatorname{Tln}\left[\mathrm{H}^{+}\right]=\mathrm{PH} \times \mathrm{k}_{\mathrm{B}} \operatorname{Tln} 10$

where $k_{B}$ is the Boltzmann constant and $T$ is the temperature. Given the fact that the high-spin ground state of the oxygen molecule is poorly described in DFT calculations, the free energy of the $\mathrm{O}_{2}$ molecule was determined by Eq. (25), ${ }^{48}$

$\mathrm{G}_{\mathrm{O}_{2}}(\mathrm{~g})=2 \mathrm{H}_{2} \mathrm{O}(1)-2 \mathrm{G}_{\mathrm{H}_{2}}+4 \times 1.23(\mathrm{eV})$

The free energy of $\mathrm{OH}^{-}$was derived as Eq. (26),

$\mathrm{G}_{\mathrm{OH}^{-}}=\mathrm{G}_{\mathrm{H}_{2} \mathrm{O}}(1)-2 \mathrm{G}_{\mathrm{H}^{+}}$

The free energy for water with gas phase was calculated at 0.035 bars because this is the equilibrium pressure in contact with liquid water at $298 \mathrm{~K}$. The free energy of gas phase water at these conditions is equal to the free energy of liquid water.

An ideal catalyst should be able to facilitate ORR above the equilibrium potential, but require all the four charge-transfer steps to have reaction free energy of the same magnitude at zero potential (i.e., $4.92 \mathrm{eV} / 4=1.23 \mathrm{eV}$ ). This is equivalent to all the reaction free energy being zero at the equilibrium potential, $1.23 \mathrm{~V}$. So, the reaction free energy of Eqs (13) to (16) for the ORR can be determined from the following equations:

$$
\begin{aligned}
\Delta \mathrm{G}_{1} & =\Delta \mathrm{G}_{\mathrm{OOH}^{*}}-4 \times 1.23(\mathrm{eV}) \\
\Delta \mathrm{G}_{2} & =\Delta \mathrm{G}_{\mathrm{O}^{*}}-\Delta \mathrm{G}_{\mathrm{OOH}^{*}} \\
\Delta \mathrm{G}_{3} & =\Delta \mathrm{G}_{\mathrm{OH}^{*}}-\Delta \mathrm{G}_{\mathrm{O}^{*}} \\
\Delta \mathrm{G}_{4} & =-\Delta \mathrm{G}_{\mathrm{OH}^{*}}
\end{aligned}
$$

The rate-determining step (RDS) is the elementary reaction with minimum reaction free energy (Eq. 31), while the overpotential is the corresponding potential obtained by Eq. (32).

$$
\begin{aligned}
& \mathrm{G}^{\mathrm{ORR}}=\min \left\{\Delta \mathrm{G}_{1}, \Delta \mathrm{G}_{2}, \Delta \mathrm{G}_{3}, \Delta \mathrm{G}_{4}\right\} \\
& \eta^{\mathrm{ORR}}=\left|\mathrm{G}^{\mathrm{ORR}}\right| / \mathrm{e}-1.23 \mathrm{~V}
\end{aligned}
$$

According to the previous reports, the RDS is commonly either the adsorption of $\mathrm{O}_{2}$ as $\mathrm{OOH}^{*}$ or the desorption of $\mathrm{OH}^{*}$ as water.

\section{Experimental indicators}

The rotating-disk electrode ( $\mathrm{RDE}$ ) measurement is one of simple and powerful methods to evaluate the electrocatalytic ORR performance of electrocatalysts. Key activity indicators of reaction kinetics can be harvested through linear scanning voltammetry (LSV) curves after adhering electrocatalysts to a typical RDE. ${ }^{49}$ For examples, onset potential $\left(E_{\text {onset }}\right)$, half-wave potential $\left(E_{1 / 2}\right)$, overpotential at a specific current density $\left(\eta_{\mathrm{j}}\right)$, diffusion-limiting current density $\left(J_{L}\right)$, kinetic-limiting current density $\left(J_{K}\right)$, the electron transferred number (n), and Tafel slope can all be derived from the measurement of polarization curves. ${ }^{50}$ The electrochemical and hydrodynamic property of electrocatalysts measured by $\mathrm{RDE}$ can be correlated to the Koutecky-Levich (K-L) equation:

$\mathrm{J}^{-1}=J_{\mathrm{k}}^{-1}+J_{\mathrm{L}}^{-1}=J_{\mathrm{k}}^{-1}+\left(\mathrm{B} \omega^{1 / 2}\right)^{-1}$

$\mathrm{B}=0.2 \mathrm{nFD}_{\mathrm{O}_{2}}^{2 / 3} \mathrm{v}^{-1 / 6} \mathrm{C}_{\mathrm{O}_{2}}$

where $\omega$ stands for the electrode rotating speed in rpm, $J$ is the current density, $B$ is the reciprocal of the slope, $C_{0}$ is the concentration of $\mathrm{O}_{2}, \mathrm{D}_{\mathrm{O}_{2}}$ is the $\mathrm{O}_{2}$ diffusion coefficient, and $v$ is the electrolyte kinematic viscosity. When the rotating speed $(\omega)$ is expressed in rpm, the coefficient is 0.2 .

By the RDE methodology, the electrocatalytic measurements are usually performed in a standard three-electrode electrochemical cell, which is connected to an electrochemical workstation. Catalyst powder is typically dispersed in a water/alcohol/Nafion ionomer solution to from an ink by ultrasonic dispersion. Then a certain amount of ink is casted and dried on the glassy carbon electrode as working electrode. Electrochemical activity of the working electrode is measured in a de-aerated or $\mathrm{O}_{2}$-saturated electrolyte (e.g., $0.1 \mathrm{M} \mathrm{KOH})$ at near room temperature $\left(25-30^{\circ} \mathrm{C}\right)$ by different electrochemical techniques. Prior to measurements, the electrolyte should be saturated with highly pure $\mathrm{N}_{2}$ or $\mathrm{O}_{2}$ for more than 20 minutes. For the typical LSV curves, the electrode usually rotates from 400 to $2500 \mathrm{rpm}$ at a scan rate, such as $5 \mathrm{mV} / \mathrm{s}$ in a certain potential range. The background current is subtracted from the measured ORR current to eliminate any contributions of capacitive current by recording the sweep profile at the same scan rate in $\mathrm{N}_{2}$-purged electrolyte.

The other important technique to estimate the electrocatalytic activity is measuring ring and disc currents by a rotating ring-disk electrode (RRDE) equipped with a coaxial Pt ring, which is used to probe the resultants generated and diffused from the disk electrode. The preparation of working electrode and measurement procedure is as same as using $\mathrm{RDE}$, except that Pt ring is usually set at a potential value of $1.3-1.5 \mathrm{~V}$ versus RHE in $0.1 \mathrm{M}$ alkaline electrolyte. Based on the measured $I_{R}$ and $I_{D}$, electron transferred number $(n)$ and the $\mathrm{H}_{2} \mathrm{O}_{2}$ yield can be calculated from Eqs (35) and (36):

$$
\begin{aligned}
& \mathrm{n}=4 \times \frac{\mathrm{I}_{\mathrm{D}}}{\mathrm{I}_{\mathrm{D}}+\mathrm{I}_{\mathrm{R}} / \mathrm{N}} \\
& \%\left(\mathrm{H}_{2} \mathrm{O}_{2}\right)=200 \times \frac{\mathrm{I}_{R} / \mathrm{N}}{\mathrm{I}_{\mathrm{D}}+\mathrm{I}_{\mathrm{R}} / \mathrm{N}}
\end{aligned}
$$

in which $\mathrm{N}$, the current collection efficiency of the Pt ring, could be regarded as 0.37 (measured from the reduction of $\mathrm{K}_{3} \mathrm{Fe}[\mathrm{CN}]_{6}$ ).

Tafel slope (b) is an important parameter to indicate the reaction pathway as well as the RDS, which is calculated according to the Tafel equation as follows:

$\eta=\mathrm{a}+\mathrm{b} \cdot \log \left(\mathrm{j} / \mathrm{j}_{0}\right)$

When $\eta$ is equal to 0 , the exchange current density $\left(j_{0}\right)$ can be derived from the above equation, which represents the intrinsic activity of electrocatalysts under equilibrium states.

Tafel slope is typically $60 \mathrm{mV} / \mathrm{dec}$ or $120 \mathrm{mV} / \mathrm{dec}$ for the electrocatalytic ORR. The former value indicates that a pseudo 2e reaction is the RDS, while the latter usually corresponds to the first-electron reduction of $\mathrm{O}_{2}$ as the rate-determining step, indicating that the subsequent reduction and $\mathrm{O}-\mathrm{O}$ bond cleaving occur easily. ${ }^{51}$

\section{ELECTROCATALYTIC MECHANISMS}

In carbon materials, the intrinsic edges including armchair edges and zigzag edges can strongly influence the electronic structure of neighboring $\mathrm{C}$ atoms. ${ }^{52}$ Because the size or electronegativity between the heteroatoms and carbon atoms is usually different, the heteroatom doping in several different configurations could also significantly alter the electron distribution of dopants and adjacent $C$ atoms via the delocalization of $\pi$ electrons, thereby affecting the physical and chemical properties. Similarly, constructing a vacancy/defect by removing a $C$ atom may not only destroy the unity of $\pi$ conjugation, but also exert a great influence on the electronic structure of adjacent $C$ atoms. 
Heteroatom doping

Pristine carbon materials including graphene, carbon black, CNTs, CNFs (carbon nanofibers), mesoporous carbon, or activated carbon, etc. are commonly inactive as electrocatalysts towards the ORR. However, the electrocatalytic activity of carbon materials can be remarkably enhanced by heteroatom doping, such as $\mathrm{N}$ doping. The introduction of heteroatoms into carbon materials can be experimentally achieved by either in situ doping in the synthesis process of carbon materials or post-treatment of the mixture of pre-synthesized carbon materials and dopantcontaining materials. The contents and chemical states of the

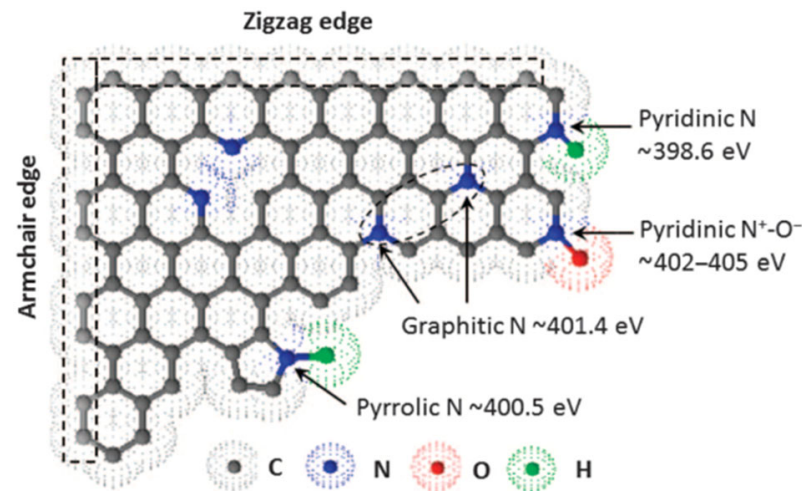

Fig. 2 Schematic illustration of the commonly doped $\mathrm{N}$ species in graphitic carbon materials and the corresponding binding energy (reproduced with permission from ref. ${ }^{10}$, Copyright ${ }^{\circ}$ AAAS 2015) dopants on the surface of heteroatom-doped carbon materials can be revealed in detail by XPS (X-ray photoelectron spectroscopy). The shape and location of peaks for each element can be probed by exposing the as-prepared doped carbon materials to $\mathrm{X}$-rays beams. The electron configuration can be facilely deduced from the peaks, of which the shape and location are sensitive to the binding energy of electrons. For more detailed atomic-scale structure information of electrocatalysts such as the coordination chemistry, atomic species, oxidation state, and bond length can be further characterized by XAS (X-ray absorption spectroscopy), ${ }^{53}$ including XANES (X-ray absorption near-edge spectroscopy) and EXAFS (extended X-ray absorption fine-structure spectroscopy).

Single doping. In general, most studies reported that the doping of $\mathrm{N}$ atoms in the $\mathrm{C}$ basal planes has distinctly boosted the ORR activity of carbon materials. However, which kind of $\mathrm{N}$ groups does function as the catalytic centers for the ORR? Is total $\mathrm{N}$ concentration important or not in the ORR process? These questions are still not clearly elucidated. There are usually four $\mathrm{N}$ species in $\mathrm{N}$-doped carbon materials, including pyridinic $\mathrm{N}$, pyrrolic $\mathrm{N}$, quaternary $\mathrm{N}$ (also called quaternary- $\mathrm{N}$ ), and $\mathrm{N}$-oxides of pyridinic $\mathrm{N}$ as shown in Fig. $2 .{ }^{10}$ Some researchers thought that pyridinic $\mathrm{N}$ functions as efficient active centers to promote the electrocatalytic ORR performance, ${ }^{11,13,54,55}$ whereas others insisted on an opinion that graphitic $\mathrm{N}$ instead of pyridinic $\mathrm{N}$ contributes dominantly to the ORR performance enhancement. ${ }^{53,56,57}$ To reconcile such controversy, a mutual transformation between graphitic $\mathrm{N}$ and pyridinic $\mathrm{N}$ through a cyclic $\mathrm{C}-\mathrm{N}$ ring opening strategy has been proposed by Kim et al. ${ }^{58}$ In addition, Ruoff's group delivered an opinion that $\mathrm{j}_{\mathrm{L}}$ and $\mathrm{E}_{\mathrm{onset}}$ are governed by graphitic- $\mathrm{N}$ and pyridinic- $\mathrm{N}$, respectively, whereas the total $\mathrm{N}$ content contributes little to the catalytic activity of carbon
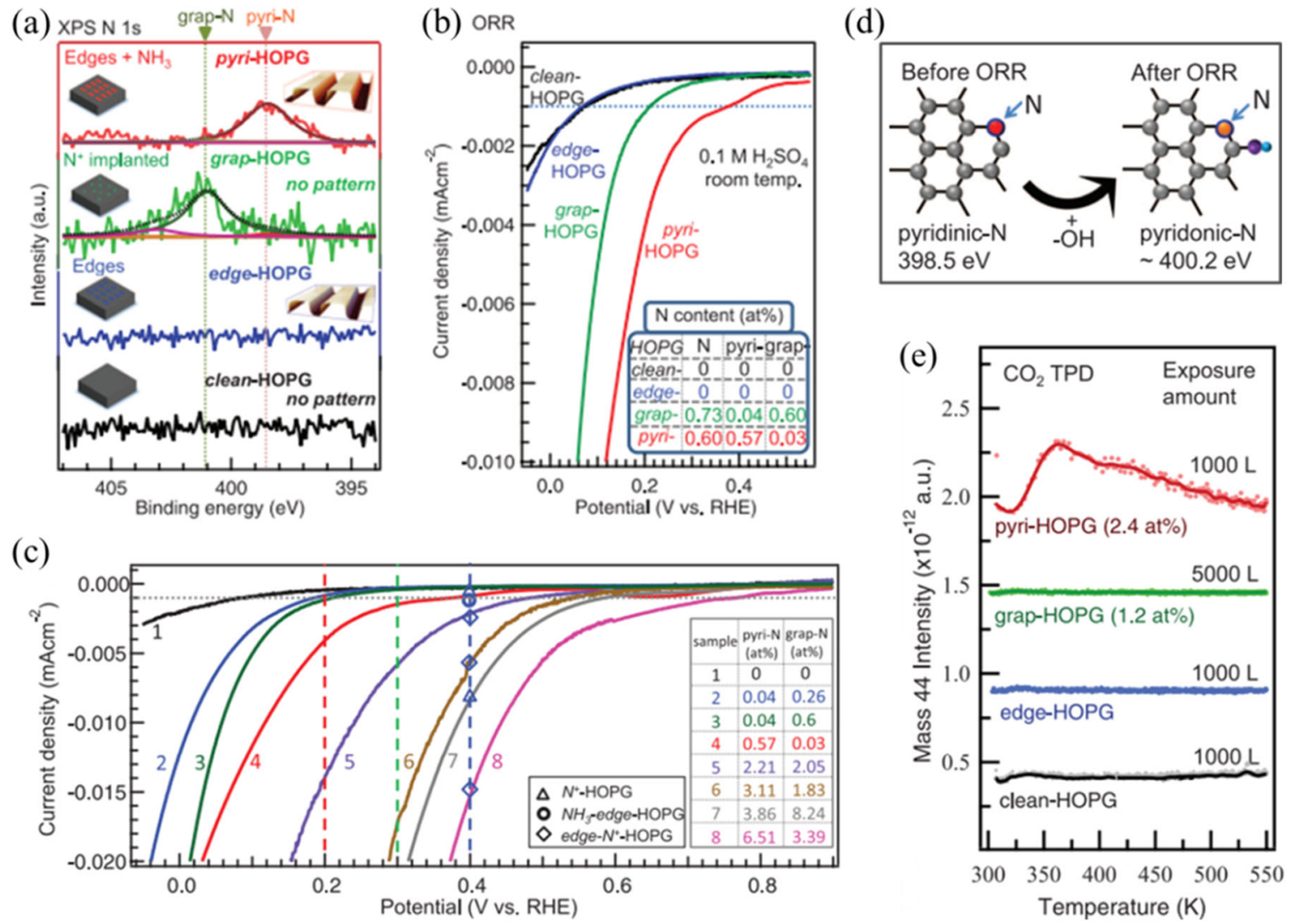

Fig. 3 a N 1 s high resolution XPS spectra; $\mathbf{b}$ The corresponding LSV curves of the electrocatalysts; the inset of $\mathbf{b}$ lists the amount of N dopants in the catalysts; $\mathbf{c}$ LSV curves of the catalysts with different $\mathrm{N}$ concentrations; $\mathbf{d}$ Scheme of the formation process of pyridonic $\mathrm{N}_{\text {; }}$ e $\mathrm{CO}_{2}$ desorption curves for the four kinds of catalysts (reproduced with permission from ref. ${ }^{44}$, Copyright ${ }^{\circ}$ AAAS, 2016) 
(a)
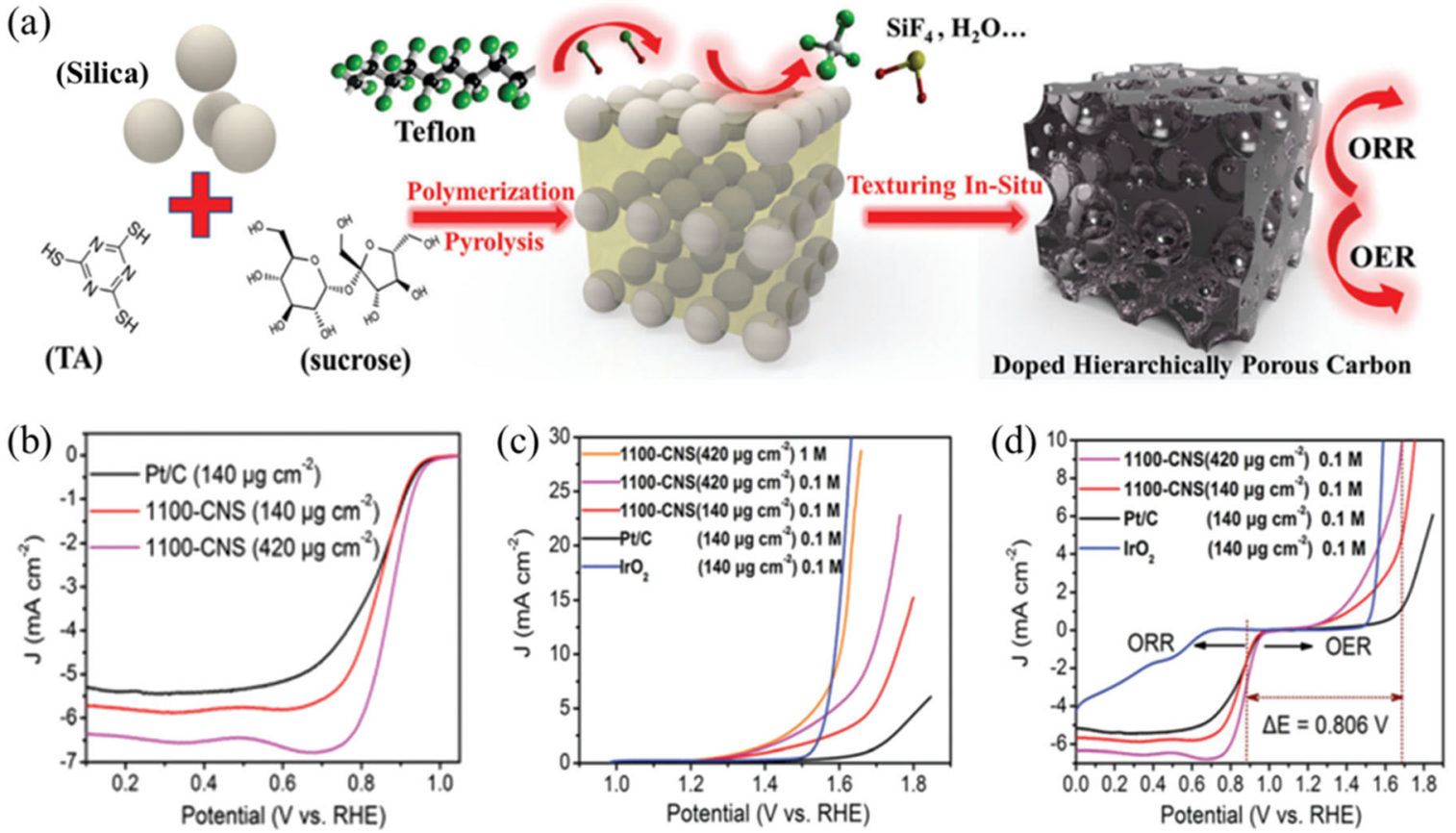

Fig. 4 a Scheme of the synthesis process of porous carbon materials with ternary dopants; $\mathbf{b}$ Polarization curves of the as-prepared 1100-CNS samples and commercial Pt/C; c LSV curves of the as-prepared 1100-CNS, Pt/C and $\mathrm{IrO}_{2}$ towards OER at $1600 \mathrm{rpm}$ in $\mathrm{KOH}$ solution with different concentrations; d The comparison of bifunctional activity of the $1100-\mathrm{CNS}, \mathrm{Pt} / \mathrm{C}$, and $\mathrm{IrO}_{2}$ samples in $0.1 \mathrm{M} \mathrm{KOH}$ electrolyte (reproduced with permission from ref. ${ }^{79}$, Copyright ${ }^{\circ}$ The Royal Society of Chemistry 2017)

materials. ${ }^{59}$ Such trade-off view also gained many researchers' favor, ${ }^{60-62}$ although Chen et al. thought that higher amount of $\mathrm{N}$ dopants in the N-doped carbon catalysts, higher electrocatalytic performance towards ORR. ${ }^{63}$ The simultaneous formation of several $\mathrm{N}$ species poses the critical challenge to elucidate the specific active site due to the difficulty of precise control of $\mathrm{N}$ species.

To elucidate the active centers of $\mathrm{N}$-containing carbon materials, Guo et al. deliberately synthesized four kinds of carbon-based electrocatalysts with well-defined $\pi$ conjugation towards ORR, on the basis of HOPG (highly oriented pyrolytic graphite): (i) pyri-HOPG, (ii) grap-HOPG, (iii) edge-HOPG, and (iv) clean-HOPG, as shown in Fig. 3a. ${ }^{44}$ From the LSV curves (Fig. 3b), they found that the current densities and concentrations of pyridinic $\mathrm{N}$ exhibit a linear relationship at every investigated potential (Fig. 3c). Such characteristic implies that the pyridinic $\mathrm{N}$ concentration solely determine the electrocatalytic activity of $\mathrm{N}$ doped carbon materials. The ex situ post-ORR XPS measurement suggests that $\mathrm{OH}$ species could react with the $\mathrm{C}$ atoms neighboring to pyridinic $\mathrm{N}$, leading to the resultant transformation from the pyridinic $\mathrm{N}$ to pyridonic $\mathrm{N}$. This means that pyridinic $\mathrm{N}$ groups themselves are not active sites, while the $\mathrm{C}$ atoms next to pyridinic $\mathrm{N}$ are active for ORR (Fig. 3d). Carbon dioxide gas desorption test shows that only pyri-HOPG with highly active ORR performance could adsorb acidic $\mathrm{CO}_{2}$ molecule. This result also demonstrates that pyridinic $\mathrm{N}$ species in the carbon matrix could create the electrocatalytic sites with high activity because of the generation of Lewis basic sites (Fig. 3e). Therefore, they concluded that Lewis basic $\mathrm{C}$ atoms neighboring pyridinic $\mathrm{N}$, not pyridinic $\mathrm{N}$ themselves, are the electrocatalytic ORR centers in $\mathrm{N}$-doped carbon materials.

Besides $\mathrm{N}$ doping, carbon materials doped by other kinds of heteroatoms (e.g., S, B, P etc.) also introduce improved ORR activity compared to the undoped counterparts. For examples, Pumera's group synthesized a series of SG by thermally exfoliating graphite oxide in different S-containing gas (e.g., $\mathrm{CS}_{2}, \mathrm{SO}_{2}$, or $\left.\mathrm{H}_{2} \mathrm{~S}\right){ }^{64}$ Compared with non-doped counterpart, the reduction potential of SG shows a positive shift of $40 \mathrm{mV}$, indicating that S doping provides an electrocatalytic sites towards ORR. Sulfurdoped graphene was also obtained by cycling Li-S batteries by Wang and co-workers, which shows a positive shift of about $60 \mathrm{mV}$ and higher current density compared to the non-doped graphene. ${ }^{21}$ Similarly, compared to pristine carbon materials, Bdoped CNTs or graphene also demonstrated improved ORR activity but less active than commercial $\mathrm{Pt} / \mathrm{C}^{16,17} \mathrm{P}$-doped graphene or $\mathrm{OMC}$ synthesized by thermal annealing of corresponding carbon sources and triphenylphosphine (TPP) also exhibited superior electrocatalytic activity to that of pristine graphene, but inferior to that of $\mathrm{Pt} / \mathrm{C}^{65,66}$ The electrocatalytic mechanism was usually explained by the similar theory to $\mathrm{N}$ doped carbon materials, such as electronegativity or electronic spin density. Overall, the physics behind the improved but not remarkable activity are not yet explained clearly. Halogen-doped carbon materials were also fabricated and investigated as the ORR electrocatalysts. ${ }^{67,68}$ For examples, edge-halogenated graphene nanoplatelets $(\mathrm{GnP})$ by halogen elements (e.g., chlorine, bromine, or iodine) were synthesized through high-energy ball milling, which were highly active to catalyze oxygen reduction with a good selectivity, but still not on par with the commercial $\mathrm{Pt} / \mathrm{C}^{24}$ The activity order, $\mathrm{Cl}-\mathrm{GnP} \ll \mathrm{Br}-\mathrm{GnP}<\mathrm{I}-\mathrm{GnP}$, is not in accordance with the charge-transfer mechanism caused by dopants with different electronegativity $\left(X_{C I}=3.16, X_{B r}=2.96\right.$, and $\left.X_{I}=2.66\right)$. In contrast, carbon blacks doped with $\mathrm{F}$ atoms with larger electronegativity $\left(X_{F}=3.98\right)$ showed distinct catalytic activity, demonstrating more positive $\mathrm{E}_{\text {onset }}$ and $\mathrm{E}_{1 / 2}$ than those of $\mathrm{Pt} / \mathrm{C}^{69}$

Binary or ternary doping. It is also noticed that upon $\mathrm{N}$ co-doping with other heteroatoms, the resultant co-doped carbon materials usually are more electrocatalytic active towards ORR than the single-doped counterpart. For examples, N, B-doped graphene (NBG) synthesized by thermal annealing the mixture of $\mathrm{GO}$ and $\mathrm{H}_{3} \mathrm{BO}_{3}$ under $\mathrm{NH}_{3}$ atmosphere, delivered better electrocatalytic performance towards ORR than the commercial Pt/C. ${ }^{27}$ Qiao's group also obtained NBG by sequentially incorporating N and B 

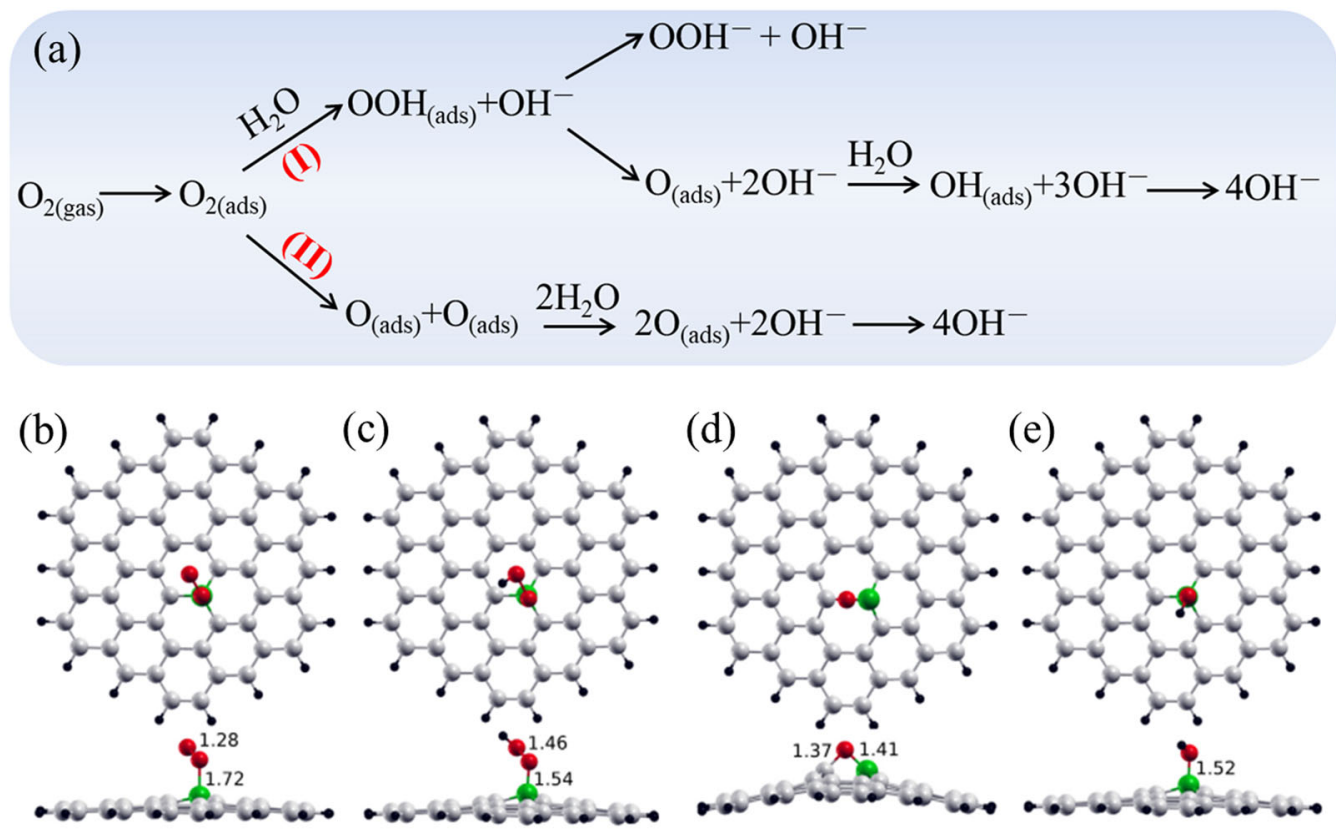

(f)
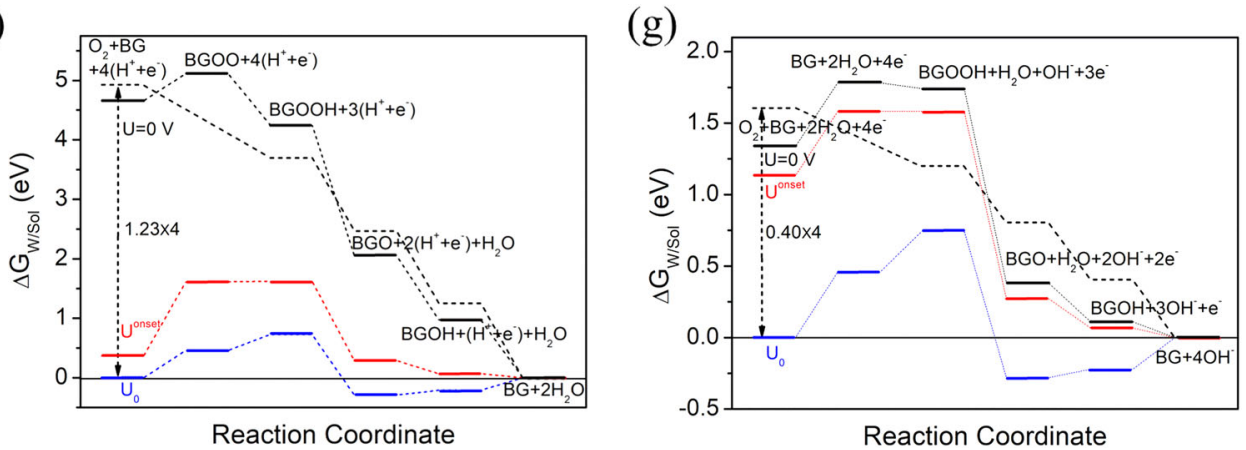

Fig. 5 a ORR pathways on N-doped graphene in alkaline electrolyte: (I) associative mechanism and (II) dissociative mechanism (reproduced with permission from ref. ${ }^{87}$, Copyright ${ }^{\circ}$ Elsevier 2011). Schematic illustration of the reaction intermediates when using BG as ORR electrocatalysts: b OO-BG, c HOO-BG, d O-BG, e HO-BG; The corresponding free energy $\left(\Delta \mathrm{G}_{\mathrm{w} / \mathrm{sol}}\right)$ diagram vs reaction steps $\mathbf{f}$ in acidic electrolytes $(\mathrm{pH}=0)$ and $\mathbf{g}$ in alkaline electrolytes $(\mathrm{pH}=14)$; The optimal electrocatalyst was displayed by dashed line (reproduced with permission from ref. ${ }^{89}$, Copyright ${ }^{\odot}$ Elsevier 2014)

into graphene domains and observed more active electrocatalysts towards ORR relative to that of single-doped graphene. ${ }^{70}$ They also found that $\mathrm{N}$, S-doped graphene (NSG) exhibited more positive $E_{\text {onset }}(-0.06 \mathrm{~V}$ vs. $\mathrm{Ag} / \mathrm{AgCl})$ than that of $\mathrm{NG}, \mathrm{SG}$, or $\mathrm{G}$ at $1600 \mathrm{rpm}$, which was comparable to commercial Pt/C $(-0.03 \mathrm{~V}$ vs. $\mathrm{Ag} / \mathrm{AgCl}) .{ }^{71} \mathrm{~A}$ series of NSG samples with different ratios were also prepared via thermal pyrolysis of several doping precursors (e.g., pyridine, thiophene, and bithiophene combined separately with dipyrrolemethane as single $\mathrm{N}$ and/or $\mathrm{S}$ precursor). ${ }^{72}$ The asprepared NSG exhibited highly electrocatalytic activity than that of only N-doped graphene. Recently, a hierarchical porous N, S codoped graphite sheets have been just reported by $\mathrm{Hu}$ and Dai, which exhibited as positive $\mathrm{E}_{1 / 2}$ as that of commercial Pt/C (ETEK). ${ }^{73}$ Incorporation of both $\mathrm{N}$ and $\mathrm{P}$ atoms into carbon materials is also an efficient approach of improving their electrocatalytic performance towards ORR. Woo's group reported that N, P codoped graphene (NPG) delivered the higher activity towards ORR in an acidic medium compared with single $\mathrm{N}$-doped graphene. ${ }^{32}$ We also fabricated $\mathrm{N}, \mathrm{X}(\mathrm{X}=\mathrm{B}, \mathrm{S}$, or $\mathrm{P})$ co-doped graphene samples via solvothermal reaction and found that the electrocatalytic activity is in the order of NSG $<$ NBG $<$ NPG, which agrees well with the previous theoretical simulation and experimental results. ${ }^{33} \mathrm{O}$ - and $\mathrm{N}$-doped mesoporous carbon materials, which were synthesized via polymerizing polyaniline in situ within the pores of mesoporous silica (SBA-15), also demonstrated more efficient electrocatalytic activity towards ORR than the commercial $\mathrm{Pt} / \mathrm{C}$ samples. ${ }^{74}$ All dual-doped graphene samples usually become more efficient than the single-doped counterparts, which may be explained by the so-called synergistic effect from two different types of doped atoms $X(S, P$, or $B)$. In these dual-doped graphene materials, $\mathrm{C}$ atom next to $\mathrm{N}$ atom is polarized, while $\mathrm{X}$ atoms facilitate the adsorption of $\mathrm{HO}_{2}$ followed by the bonding with active sites. $^{70}$

Ternary atomic incorporation of boron, phosphorus, and nitrogen atoms within carbon materials would result in effective improvement of catalytic activity due to the enhanced asymmetry of spin density from additional dopants, such as boron and/or phosphorus. ${ }^{34} \mathrm{Yu}$ and co-workers incrementally doped $\mathrm{P}$ atoms into $\mathrm{N}, \mathrm{S}$ co-doped graphene to achieve a ternary-doped graphene (NSPG), demonstrating a distinct electrocatalytic activity towards ORR, two times higher than binary NSG, and five times higher than PG and even outperforming the $\mathrm{Pt} / \mathrm{C}$ samples in alkaline solutions. ${ }^{75} \mathrm{~N}, \mathrm{~B}$, and $\mathrm{P}$ ternary-doped graphene (NBPG) samples were prepared by utilizing $\mathrm{NH}_{3}$ as a $\mathrm{N}$ precursor, and boron phosphate as both $\mathrm{B}$ and $\mathrm{P}$ source, which also exhibited mainly four-electron pathway in alkaline electrolyte. ${ }^{76} \mathrm{~N}, \mathrm{~S}$, and $\mathrm{P}$ co-doped carbon materials with porous structure carbonized from MOFs (metal-organic frameworks) also showed as high $\mathrm{E}_{\text {onset }}$ as 
(a)

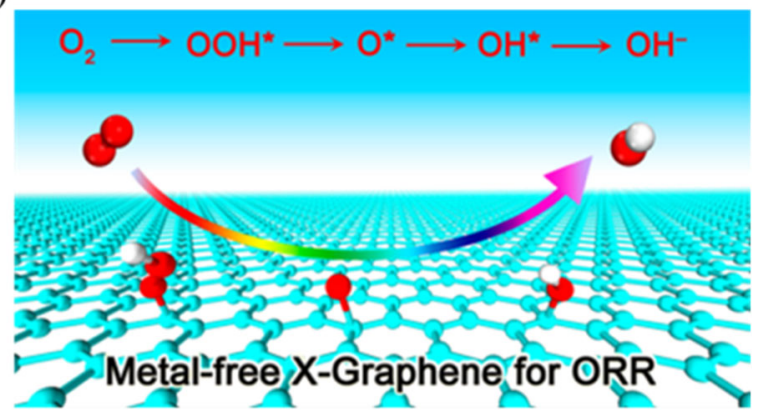

(b)

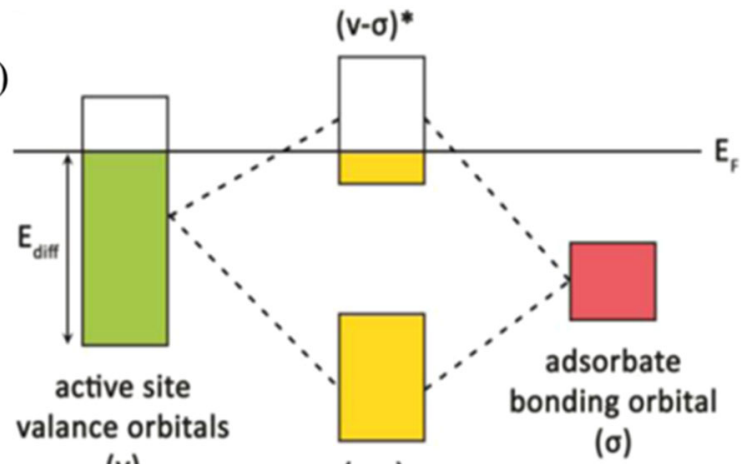

(v)

( $v-\sigma)$

(б)

Fig. 6 a Scheme of heteroatom-doped graphene $(X=B, N, P, O, S)$; $b$ Schematic illustration of orbital hybridization of active-site valence band and bonding orbital of adsorbates (reproduced with permission from ref. ${ }^{92}$, Copyright ${ }^{\odot}$ American Chemical Society 2014)

the commercial Pt/C electrocatalysts. ${ }^{77}$ Compared with other $\mathrm{N}$ doping types, the amount of pyridinic- $\mathrm{N}$ persentages increase due to the $\mathrm{B}$ doping, while the $\mathrm{P}$ doping induces charge redistribution of $C$ atoms as well as a great amount of edge sites due to introduction of split and wrinkles. ${ }^{34}$ In addition, the degree of $\mathrm{sp}^{2}$ C structure in such ternary-doped carbon materials is also enhanced, which is beneficial for the electrical conductivity.

Recently, Qu et al. developed N, S-co-doped carbon nanosheets (NSCN) by pyrolyzing the graphene oxide-polydopamine hybrids. The resultant mesoporous NSCN nanosheets exhibited superior bifunctional electrocatalytic activity with favorable kinetics towards ORR and oxygen evolution reaction (OER) ${ }^{78}$ Zhi's group $^{\prime}$ fabricated N, S, O ternary-doped carbon materials with hierarchical porosity by a direct pyrolysis procedure (Fig. 4a). ${ }^{79}$ In the synthesis process, the silica spheres embedded precursor monomers are mixed together with Teflon powder ( $5 \mathrm{~mm}$ ), and pyrolyzed to form micro-, meso-, and macroporous carbon materials doped by nitrogen, sulfur as well as oxygen atoms. The $1100-C N S$ sample obtained at $1100^{\circ} \mathrm{C}$ delivers a good electrocatalytic ORR activity, remarkably exceeding the benchmark $\mathrm{Pt} / \mathrm{C}$ with the same loading mass (Fig. 4b). Polarization curves indicated that the 1100-CNS sample with the loading of $420 \mu \mathrm{g} / \mathrm{cm}^{2}$ holds the superior OER performance (only $70 \mathrm{mV}$ overpotential and $1.69 \mathrm{~V}$ at $10 \mathrm{~mA} / \mathrm{cm}^{2}$ in 0.1 basic solution) to $\mathrm{Pt} / \mathrm{C}$ sample (Fig. 4c). The as-prepared sample also displays lower onset potential than the benchmark catalyst $\mathrm{IrO}_{2}$, though the current density is a little low at larger overpotentials (Fig. 4c). Another important indicator to judge the performance of a bifunctional electrocatalyst toward OER and ORR is the difference between the potential at $10 \mathrm{~mA} / \mathrm{cm}^{2}\left(E_{j=10}\right)$ for OER and the $E_{1 / 2}$ for ORR (i.e., $\Delta E=E_{j=10}-E_{1 / 2}$ ). The difference of the 1100 -CNS sample is $\sim 0.81$ and $0.72 \mathrm{~V}$ in $0.1 \mathrm{M}$ and $1 \mathrm{M} \mathrm{KOH}$, respectively (Fig. 4c, d). Such good performance could arise from the synergistic effects of these three types of heteroatoms. Namely, the $\mathrm{N}$ species with strong electron-accepting ability can

attract electrons from the adjacent $\mathrm{sp}^{2}$-bonded $\mathrm{C}$ atoms and lead to redistribution of charge density, while $S$ atoms cause the mismatch of outermost orbitals of $\mathrm{S}$ and $\mathrm{C}$ and become positively charged. $^{78}$ Oxygen-containing species can highly alter the hydrophility of carbon materials and make the catalytic surfaces more accessible, thus boosting the catalytic kinetics.

Theoretical simulation. Theoretical calculations based on quantum chemistry provide a platform to study the kinetics of a catalytic reaction. ${ }^{80,81}$ Different descriptors of intrinsic catalytic activity have been developed to uncover the underlying principle on the catalytic mechanisms by the density functional theory (DFT) calculations, such as d-band center $\left(\varepsilon_{\mathrm{d}}\right)$ of a metal atom's for metal surface ${ }^{82}$ and $\sigma^{*}$-orbital $\left(e_{g}\right)$ occupation for perovskites. ${ }^{83}$ But it is not valid to assess the catalytic activity of metal-free carbon materials without d electrons. Early in 2009, single-walled carbon nanotubes (CNTs) with or without $\mathrm{N}$ doping were studied using a cluster approach with the B3LYP hybrid DFT by Dai and Xia et al, which opened a new door to deeply understand the electrocatalytic mechanism on heteroatom-doped carbon materials. ${ }^{9}$ These results suggest that the highly positive charge density of carbon atoms adjacent to nitrogen dopants can neutralize strong electronic affinity derived from doped $\mathrm{N}$ groups, while $\mathrm{O}_{2}$ chemisorption mode are also changed by nitrogen doping.

In carbon-based catalysts, heteroatom-doped graphene is a good model to investigate the electrocatalytic processes. ${ }^{38,84-86}$ For N-doped graphene, Bao's group found that the energy barrier of the first step for associative mechanism (the $\mathrm{O}_{2 \text { (ads) }}$ hydrogenation to form $\left.\mathrm{OOH}_{(\mathrm{ads})}\right)$ is $0.51 \mathrm{eV}$, much lower than that of dissociative mechanism (1.56 eV, $\mathrm{O}_{2 \text { (ads) }}$ dissociation) as shown in Fig. $5 a .{ }^{87}$ Therefore, the former reaction mechanism is more energetically favorable than the latter one. And the overall barrier to remove $\mathrm{O}_{(\mathrm{ads})}$ species is about $0.78 \mathrm{eV}$, which is the RDS for ORR catalyzed by N-doped graphene. Chai et al. predicted that only the Stone-Wales defects created by a N-pair doping work as highly catalytic centers and the electrocatalytic ORR performance can be adjusted by the curvature surrounding the catalytic center. ${ }^{88}$ Fazio et al. presented a detailed investigation on the electrocatalytic process of BG towards ORR and identified all the intermediates and transition structures. ${ }^{89}$ They studied all the possible reaction pathways of the reaction, and also found that the associative pathway favors more energetically than dissociative one. The corresponding ball-and-stick models for various intermediate reaction species at every reaction step and final state are illustrated in Fig. 5b-e. The overall reaction steps in either acidic or alkaline electrolyte are shown in Fig. $5 f$, g, respectively. In acidic solution $(\mathrm{pH}=0)$, making the overall reduction process downhill requires to overcome an overpotential of $0.29 \mathrm{~V}$. Analogously, the $0.28 \mathrm{~V}$ overpotential is needed, corresponding to $\mathrm{E}_{\mathrm{onset}}=0.05 \mathrm{~V}$ under $\mathrm{pH}=14$.

Molecular $\mathrm{O}_{2}$ chemisorption has been simulated on $\mathrm{N}, \mathrm{B}, \mathrm{O}-$ doped, and non-doped edge sites of carbon materials as the first reaction step on the virtue of DFT. ${ }^{90}$ The simulation results show that O-doped edges of $C$ basal plane would become irreversibly oxidation state and accelerate the chemical degradation of microstructure of carbon materials. The main drawback of $\mathrm{B}$ doped carbon materials is the stronger binding of boron atom to oxygen than to carbon atoms, resulting in the formation of various $\mathrm{B}-\mathrm{O}-\mathrm{C}$ species and damage of microstructure of B-doped carbon materials. A comparative simulation of oxygen reduction on $\mathrm{N}, \mathrm{B}$, or P-doped graphene demonstrated that the P-doped graphene possesses the most efficient catalytic activity. ${ }^{91}$ As shown in Fig. 6a, Qiao's group investigated the electrocatalytic activity of doped graphene with five non-metallic dopants $(X=B, N, P, O$, and $S)$ and the relationship of molecular valence orbital levels and binding strength of active atomic sites. ${ }^{92}$ The orbital energy difference $\left(E_{\text {diff }}\right)$ between the lowest active-site valence band and the highest valence band for $2 \mathrm{D}$ carbon domain $\left(\mathrm{E}_{\mathrm{F}}\right)$ is proposed 

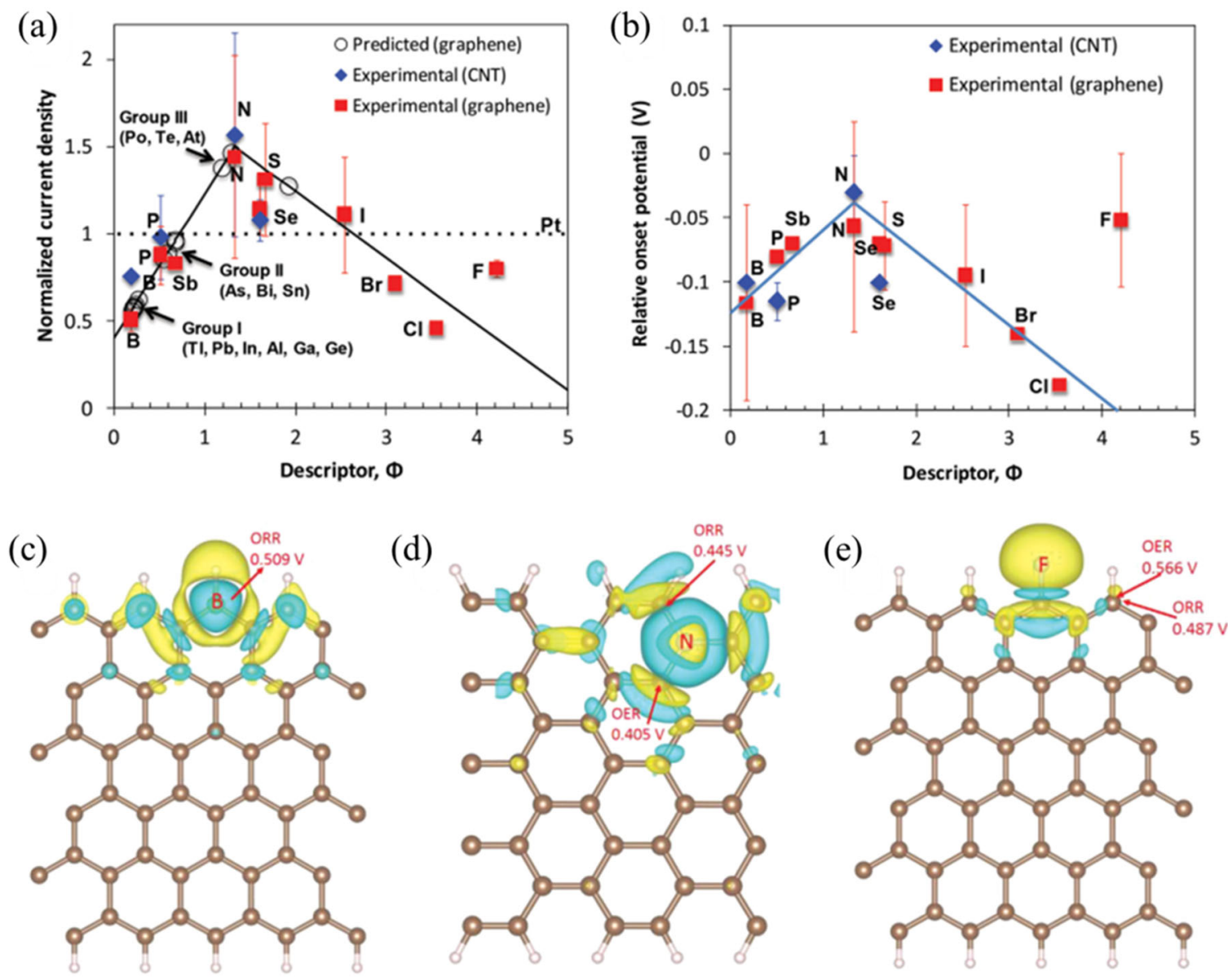

Fig. 7 a Experimental values of limiting current density based on experimental LSV curves and theoretical predictions; $\mathbf{b}$ experimentally measured relative $E_{\text {onset }}$ to that of $\mathrm{Pt} / \mathrm{C}$ catalyst, as a function of descriptor $(\Phi)$ for carbon materials doped by $p$-block elements. Differential charge density distributions between non-doped graphene and $\mathbf{c}$ B-, $\mathbf{d} \mathrm{N}$-, or e F-doped graphene. The values with plus or minus represent the electron quantities marked by yellow and blue colors, respectively. The isosurface value is set to 0.0015 . C atom and $\mathrm{H}$ atom are displayed by brown and white balls, respectively (reproduced with permission from ref. ${ }^{93}$, Copyright ${ }^{\circ}$ WILEY-VCH 2015)

to quantitively stand for the valence orbital level. The bonding $(\mathrm{v}-\sigma)$ and anti-bonding $(\mathrm{v}-\sigma)^{*}$ states could be built due to the hybridization of active-site valence band $(v)$ and the bonding $(\sigma)$ orbital of adsorbates, as illustrated in Fig. 6b. Therefore, a linear relationship is formed between $\Delta \mathrm{G}_{\mathrm{OH}^{*}}$ data and $\mathrm{E}_{\text {diff }}$ for different kinds of active sites on the doped graphene. According to this principle, a better graphene-based electrocatalyst (e.g., X-doped graphene) with higher valence orbital levels of active atomic sites, will give rise to a lower $E_{\text {diff }}$ and result in stronger adsorption for O-containing species (e.g. $\mathrm{OOH}^{*}$ and $\mathrm{OH}^{*}$ ), thus exhibiting higher ORR activity.

Recently, Xia's group introduced a dimensionless factor as indicator to describe the bifunctional electrocatalytic performance of carbon materials doped by $\mathrm{p}$-block elements towards ORR/OER, by which $\mathrm{X}$ represents $\mathrm{p}$-block elements including $\mathrm{N}, \mathrm{B}, \mathrm{P}, \mathrm{S}, \mathrm{Si}, \mathrm{Se}$, $\mathrm{Sb}, \mathrm{F}, \mathrm{Cl}, \mathrm{Br}, \mathrm{I}, \mathrm{POH}, \mathrm{SOH}, \mathrm{PO}_{2}, \mathrm{SeO}_{2}$, and $\mathrm{SO}_{2}$, etc. ${ }^{93}$ The indicator $(\Phi)$ is referred as to some relationship of electron affinity (AX) and relative electronegativity $\left(\mathrm{E}_{\mathrm{X}}\right)$, shown below:

$\Phi=\left(E_{x} / E_{C}\right) \times\left(A_{x} / A_{C}\right)$

where $E_{X}$ is the electronegativity of the element $X$, while $A_{X}$ is the electron affinity of $X$.

As shown in Fig. 7a, the volcano relationship based on the normalized current density of carbon materials doped by $\mathrm{p}$ elements as a function of $\Phi$ is consistent with the experimentally measured values, which are normalized by the benchmark current density of $\mathrm{Pt} / \mathrm{C}$ at $0.5 \mathrm{~V}$ vs SCE (saturated calomel electrode).
Analogous volcano relationship between $\mathrm{E}_{\text {onset }}$ and $\Phi$ shows good consistence with the experimental data too (Fig. 7b). Based on the fitting lines of experimentally measured data, they predicted that those elements with $\Phi<1$ themselves $(B, P$, etc) could serve as the reactive sites towards ORR (Fig. $7 \mathrm{c}$ ), while the dopants with $\Phi>1$ $\left(\mathrm{N}, \mathrm{S}\right.$, halogen, etc) could not work. For $\mathrm{X}-\mathrm{O}_{2}$ and $\mathrm{X}-\mathrm{OH}$ doping, dopants themselves are also the active centers. Interestingly, $\mathrm{N}$ doping into graphene create two important reactive centers at different locations towards OER/ORR (Fig. 7d), whereas halogen doping produces a catalytic site towards ORR and OER at the same spot (Fig. 7e). Generally, the electrocatalytic sites induced by all pelements doping are $\mathrm{C}$ atoms adjacent to the dopants. $\mathrm{Li}$ et al. proposed that the binding energy of ${ }^{*} \mathrm{OH}\left(\mathrm{E}_{\mathrm{b}\left({ }^{*} \mathrm{OH}\right)}\right)$ on heteroatomcontaining graphene could be employed as an effective indicator to describe the ORR performance. ${ }^{94}$ The electrocatalysts have the smallest overpotential when $\mathrm{E}_{\mathrm{b}\left({ }^{*} \mathrm{OH}\right)}$ appears at the vicinity of $\sim 2.60 \mathrm{eV}$, and the ORR performance of such heteroatomincorporated graphene could be determined by occupied states at the Fermi level, which governs charge transportation from electrocatalyst surface to intermediate species during the ORR process.

\section{Intrinsic defects}

Besides heteroatom doping, intrinsic defects (e.g., edges) can also modulate the surface nature and electronic structure of carbon materials. ${ }^{40}$ The introduction of defect regions in a $\mathrm{sp}^{2}-\mathrm{C}$ matrix 

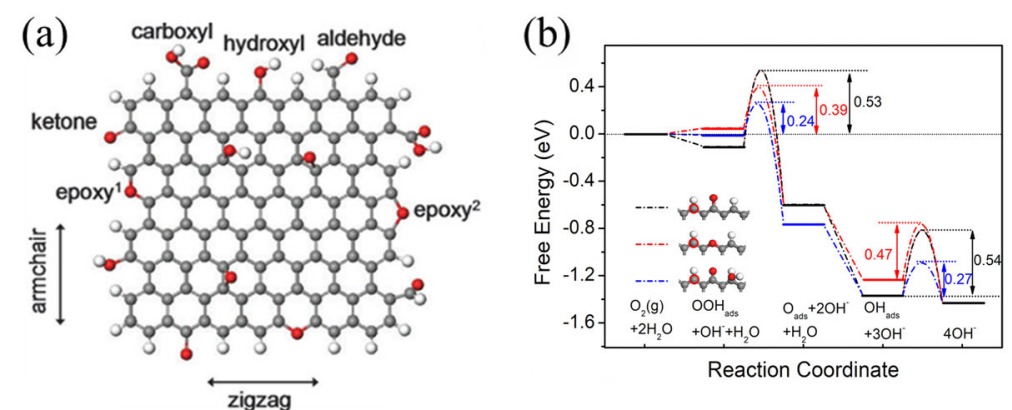

(c)

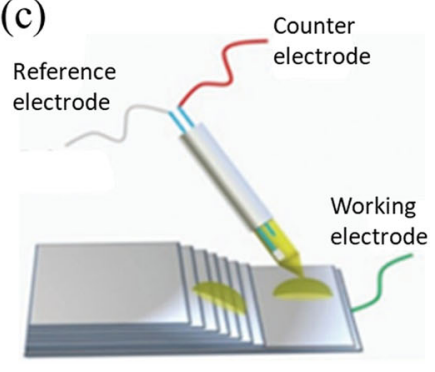

(d)

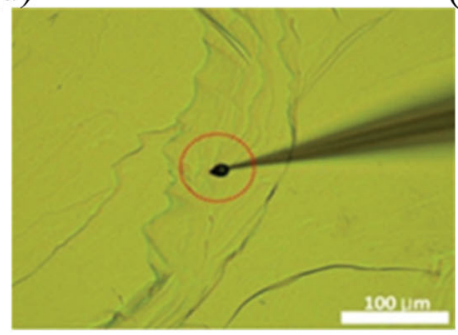

(e)

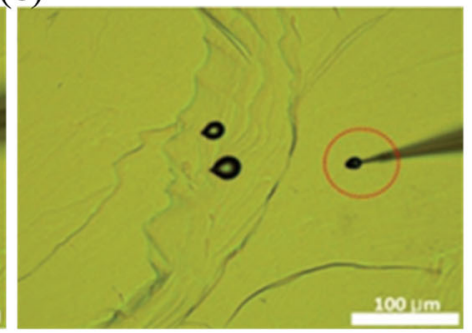

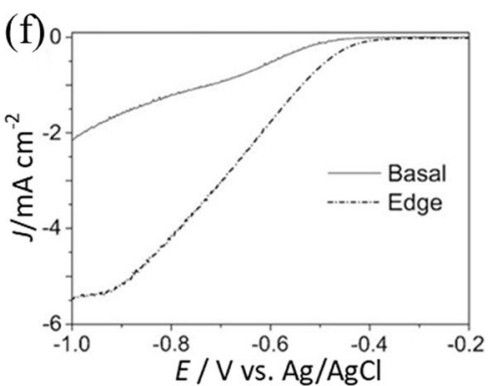

Fig. 8 a Scheme of graphene containing of armchair and zigzag edges with various O-containing species. Carbon, oxygen, and hydrogen are represented by gray, red, and white spheres, respectively. b Free energy diagram with each reaction step on the graphene with zigzag edges. The red circles indicate the active sites in the inset (reproduced with permission from ref. ${ }^{95}$, Copyright ${ }^{\circ}$ The Royal Society of Chemistry 2011 ). c Scheme of microapparatus for the electrochemical measurement towards ORR; Optical photographs of the $\mathbf{d}$ edges and e basal plane of HOPG as the working electrode, respectively. $\mathbf{f ~ L S V ~ c u r v e s ~ f o r ~ a i r - s a t u r a t e d ~ d r o p l e t ~ l o c a t e d ~ e i t h e r ~ o n ~ t h e ~ e d g e ~ ( s o l i d ~ l i n e ) ~ o r ~ t h e ~ b a s a l ~ p l a n e ~}$ (dotted line) of the HOPG, respectively (reproduced with permission from ref. ${ }^{97}$, Copyright ${ }^{\circledR} 2014$ WILEY-VCH)

may also interrupt the integrity of $\pi$ conjugation similar to the effect of heteroatom doping, which induces the charge polarization of carbon atoms to generate strong adsorption to the Ocontaining species during the ORR. ${ }^{39}$ It is crucial to clarify the contribution of typical carbon defects for developing more active carbon-based electrocatalysts towards ORR.

Deng et al. carried out DFT simulations to elucidate the catalytic mechanism on graphene nanoribbons (GNRs) containing both zigzag and armchair edges as shown in Fig. $8 .{ }^{95}$ It was found the armchair edges and the frequently concomitant $\mathrm{O}$-containing species (e.g., $-\mathrm{COOH},-\mathrm{CHO},-\mathrm{C}=\mathrm{O},-\mathrm{C}-\mathrm{O}-\mathrm{C}-$, and $-\mathrm{OH}$ ) (Fig. 8a) are inactive towards ORR, whereas the zigzag edges both with or without O-containing species are active. As shown in Fig. 8b, on these zigzag sites, energy barriers are scarcely observed for steps

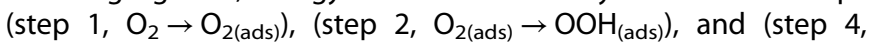
$\left.\mathrm{O}_{(\text {ads })} \rightarrow \mathrm{OH}_{(\mathrm{ads})}\right)$. However, formation of $\mathrm{O}_{(\mathrm{ads})}$ species in step 3 $\left(\mathrm{OOH}_{(\mathrm{ads})} \rightarrow \mathrm{O}_{(\mathrm{ads})}\right)$ on the edge sites of $-\mathrm{C}=\mathrm{O}$ and $-\mathrm{C}-\mathrm{O}-\mathrm{C}-$ needs to overcome a barrier of 0.53 and $0.54 \mathrm{eV}$, while for $\mathrm{OH}^{-}$ ions in step $5\left(\mathrm{OH}_{(\text {ads })} \rightarrow \mathrm{OH}^{-}\right)$, the energy barrier is 0.24 and $0.27 \mathrm{eV}$, respectively. Experimentally, Jeon et al prepared graphene nanoplatelets (GnPs) with selective edges via dry-ball-milling, where different functional groups can be anchored. ${ }^{96}$ They found that despite no heteroatom doping, the newly prepared edges with polar nature dominantly regulate the ORR performance of $\mathrm{GnPs}$ in alkaline solutions. Shen et al. experimentally investigated the activity of different components of HOPG by constructing micro-electrochemical testing device as shown in Fig. 8c, and proved that the edges exhibit higher catalytic activity than the basal plane of HOPG towards ORR (Fig. $8 \mathrm{~d}-\mathrm{f}$ ). ${ }^{97}$ Wang and coworkers demonstrated that GQDs loaded on GNRs showed almost identical $E_{1 / 2}$ to that of benchmark $\mathrm{Pt} / \mathrm{C}^{98}$ Electron microscopy revealed that large amount of GQDs/GNRs surfaces and their interfaces provide abundant surface/edge defects, which serve as highly active sites for ORR.
Similarly, Jiang and co-workers successfully synthesized nondoped carbon nanocages (CNCs) with large amount of defects but without any dopants by utilizing $\mathrm{MgO}$ particles as in situ templates. $^{39}$ The as-obtained defective CNCs demonstrated efficient catalytic activity towards ORR, which was more active than B-doped CNTs and as active as N-doped carbon materials. The good activity can be credited to pentagon defects and zigzag edges as revealed by DFT calculations. Three-type defects can be found in the CNCs as demonstrated in Fig. 9a, b, including (I) the pentagonal defects in the corners, (II) the edge defects due to the broken fringes, and (III) the hole defects ascribed to the micropores. Free-energy diagram simulated by DFT shows that zigzag edge defects and pentagonal defects possess the lower energy barriers (Fig. 9c). Tang et al synthesized defect-rich graphene mesh (GM) and N-doped GM (NGM), respectively, as shown in Fig. 9d. ${ }^{99}$ They employed direct sticky rice as carbon precursor, and melamine as nitrogen source, and magnesium hydroxide as template and carbonized the mixture at high temperature to obtain NGM. As shown in Fig. 9e, the asprepared NGM contains different types of carbon defects (C5, five- $C$ ring; $C 7$, seven- $C$ ring; $C 5+7, C 5$ ring adjacent to $C 7$ ring) and $\mathrm{N}$-containing groups $(\mathrm{Q}$, quaternary $\mathrm{N}$ on the edge; $\mathrm{PR}$, pyrrolic N; PN, pyridinic N; QN, quaternary $\mathrm{N}$ in the bulk phase). It was found that either edges or topological defects are more active than the N-doped sites for both ORR and OER. This is because the adjacent $C$ rings generate spatial curvatures inducing different electron densities and form a permanent weak dipole moment, thus resulting in a moderate adsorption and excellent activity. An optimal binding energy at the peak of volcano plots is achieved by the regulation of the topological defects $(\mathrm{C} 5+7)$ (Fig. 9f), rendering highly electrocatalytic ORR/OER activity. However, the binding of $\mathrm{OH}$ species to quaternary $\mathrm{N}$ sites is too weak, while the adsorption is too strong on the PR, PN, and QN sites. These results show that the $C 5+7$ defects are the optimal active sites for the bifunctional electrocatalysis toward both ORR and OER. Fig. $9 g$ 
(a)

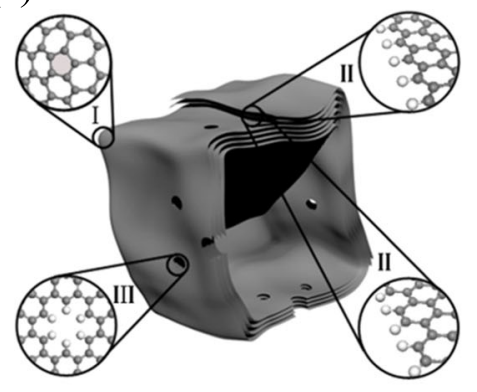

(b)

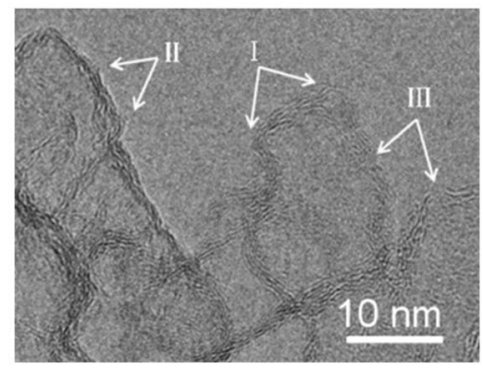

(c)

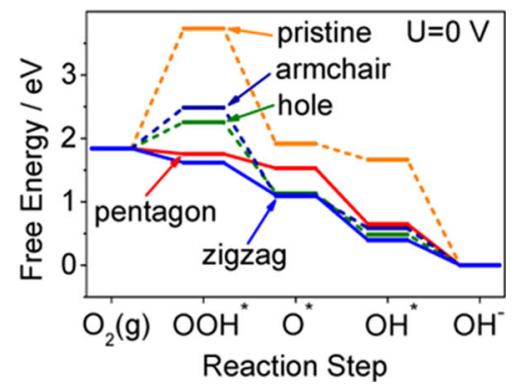

(d)

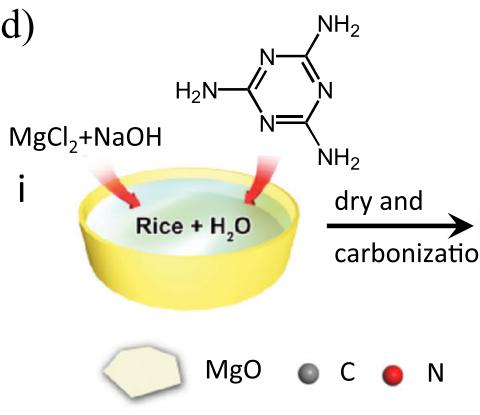

(e)

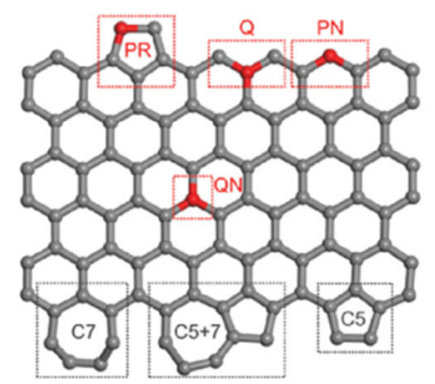

(f)

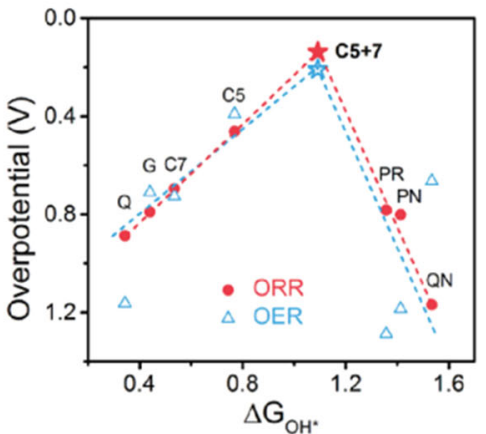

(g)

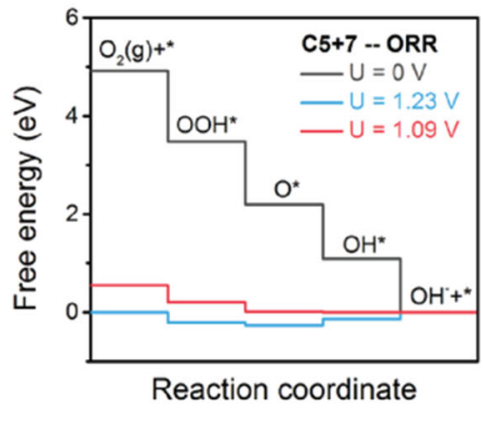

Fig. 9 a Schematic illustration of microstructure of defective carbon nanocage b corresponding HRTEM image, (c) Free energy of different defects along the reaction steps by DFT calculations considering the solution effect at $298.15 \mathrm{~K}$, where " $\mathrm{g}$ " and "*" represent the gaseous state and chemisorption, respectively (reproduced with permission from ref. ${ }^{39}$, Copyright ${ }^{\odot}$ The Royal Society of Chemistry 2015). d Schematic of the fabrication of NGM materials. e Scheme of GNR with different N-containing species or topological defects. $\mathbf{f} V_{0}$ lcano plots ( $\eta$ vs $\Delta G_{\mathrm{OH}^{*}}$ ) of different defects and $\mathrm{N}$ species in GNRs towards ORR and OER $\mathbf{g}$ Free energy versus different reaction coordinate on $\mathrm{C} 5+7$ defect towards $\mathrm{ORR}$ at $\mathrm{pH}=0$. (Reproduced with permission from ref. ${ }^{99}$, Copyright ${ }^{\circ}$ WILEY-VCH 2016)

shows the free energy diagram of reaction coordinate on activesite $\mathrm{C} 5+7$ towards ORR at $\mathrm{pH}=0$. As the potential decreases, the removal of $\mathrm{OH}^{-}$ions in the last step becomes degressive, which means it is the RDS for GNRs with $\mathrm{C} 5+7$ defects.

Yao's group have studied intensively the influence of defects of carbon materials on the ORR activity too. ${ }^{40}$ The defects with 585 configurations on graphene (G585) were predicted by the first principles calculations to be more active relative to $\mathrm{N}$ doping towards ORR. Porous carbon materials derived from a Zn-based MOF containing carbon and oxygen only, exhibit high catalytic activity towards ORR, suggesting that the defects arising from the removal of $\mathrm{Zn}$ atoms are responsible for the catalytic centers. ${ }^{100} \mathrm{~A}$ kind of renewable porous carbon material prepared by $\mathrm{KOH}$ activation also delivers a positive onset potential of $0.89 \mathrm{~V}$ (vs. $\mathrm{RHE}$ ) and half-wave potential of $0.79 \mathrm{~V}$ (vs. RHE). ${ }^{101}$ The highly porous structure also endowed inert activated carbon materials with high electrocatalytic activity towards ORR by making unique defects in the carbon materials via a simple process consisting of $\mathrm{N}$ doping and subsequent removal. ${ }^{102}$ Recently, they synthesized defective graphene (DG) from $\mathrm{N}$-doped precursor via a similar process (Fig. 10a) and assessed the ORR performance of different defects in DG through direct observations by using aberrationcorrected HR-TEM. ${ }^{103}$ Not only basic defects, but also different combinations of basic defects are found to be most close to the lattice vacancies (Fig. 10b). Based on $\mathrm{E}_{1 / 2}, \mathrm{j}_{\mathrm{L}}$ and Tafel slope (b), DG exhibits superior activity to $\mathrm{N}$-doped graphene (Fig. 10c), implying that the defects are intrinsically active towards ORR in DG. DFT calculation indicates that five types of atomic defect site $(5-1,585$ 1, 585-3, 7557-1, and 7557-4, Fig. 10d-f) hold highly ORR activity. Among them, edges 5-1 showing the lowest activation energy $(0.47 \mathrm{eV})$ is the most efficient ORR centers under $\mathrm{pH}=13$, followed by 7557-1 having a little larger energy barrier of $0.483 \mathrm{eV}$ (Fig. $10 \mathrm{~g}$ ). Both experimental and theoretical data elucidated that the defects in carbon materials are active sites, because they can modulate the local electron distribution and perturb the physicochemical property of graphene surface, such as adjusting the specific surface area and hydrophobicity. ${ }^{104}$ 
(a)

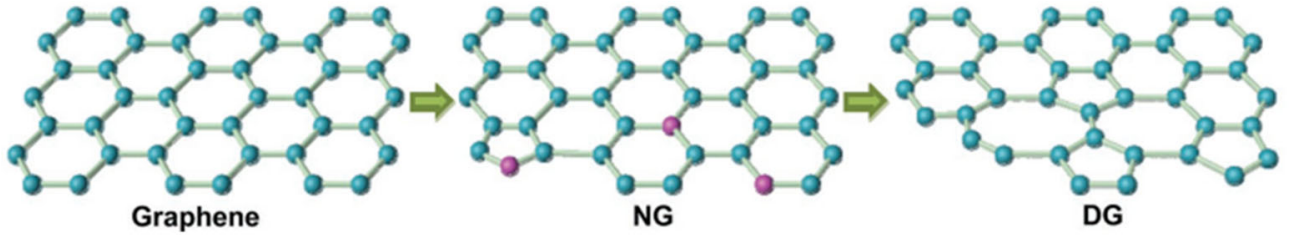

(b)

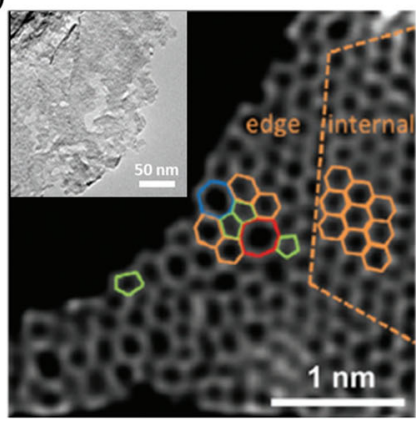

(e)

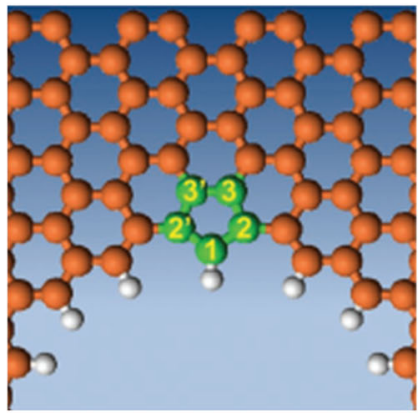

(c)

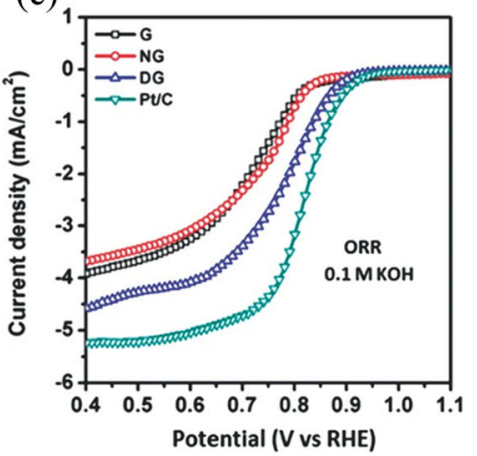

(f)

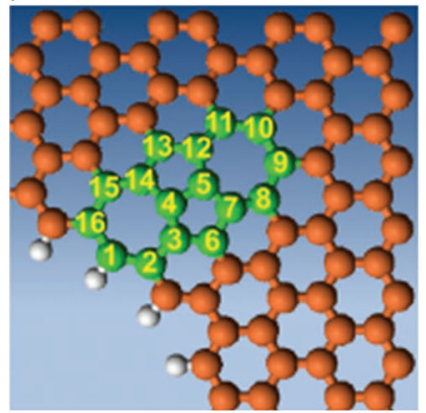

(d)

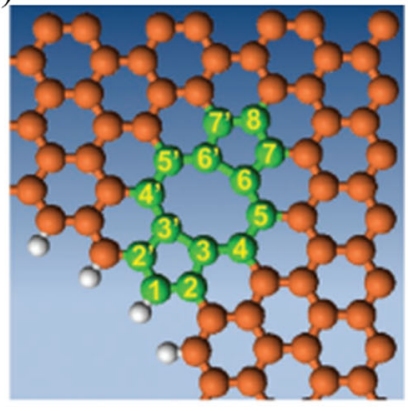

(g)

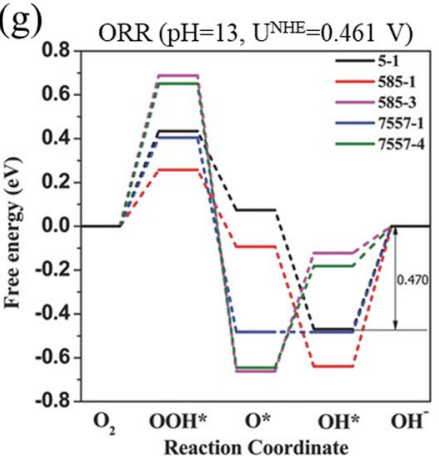

Fig. 10 a Scheme of the formation process of defective graphene $\mathbf{b}$ HAADF image of DG. The orange, green, blue, and red colors represent hexagons, pentagons, heptagons, and octagons, respectively. c LSV curves of the pristine graphene, NG, and DG. Scheme of d edge pentagon, e 5-8-5 defect, and f 7-55-7 defect. g Free energy profile for the reduction steps (reproduced with permission from ref. ${ }^{103}$, Copyright ${ }^{\circ}$ WILEY- $^{-}$ $\mathrm{VCH} 2016)$

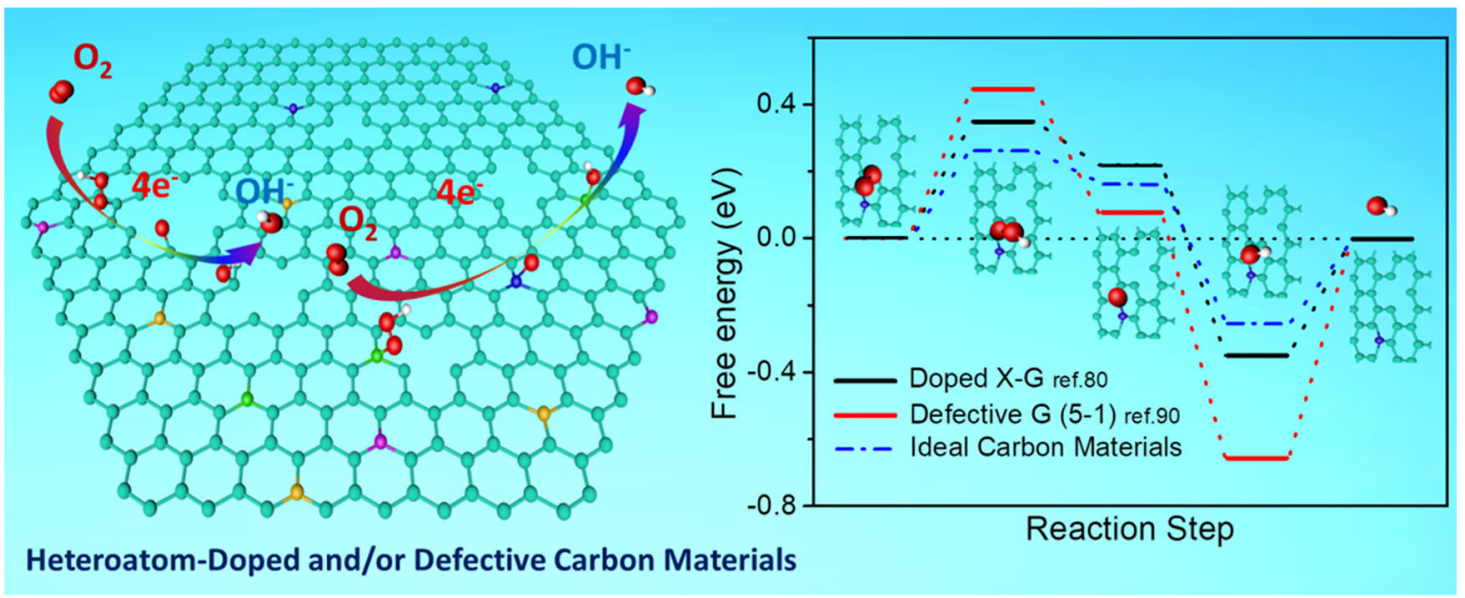

Fig. 11 The combination of heteroatom doping and defects boosts electrocatalytic ORR activity of carbon materials

\section{CONCLUSIONS AND PERSPECTIVES}

In summary, we reviewed the latest advance in the research of metal-free carbon materials as ORR electrocatalysts, especially the mechanistic understanding on the electrocatalysis. Significant progress on the mechanisms has been achieved from the finding of highly efficient $\mathrm{N}$-doped CNT to the recently renascent defective carbon materials. As a result, the intentional introduction of both heteroatoms and defects into carbon materials could be a 
promising strategy to create catalytic active sites and boost the electrocatalytic kinetics by a preferential four-electron pathway as illustrated in Fig. 11. The synergistic effect of doping and defects would further lower the free energy and reaction overpotential, thus endowing such carbon materials with the potential to outperform the state-of-the-art $\mathrm{Pt} / \mathrm{C}$ electrocatalyst in the catalytic activity. ${ }^{105,106}$ A good example has been demonstrated by Wang et al., which is pyridinic-N-dominated doped DG serving as an excellent bifunctional electrocatalyst towards ORR and OER in rechargeable $\mathrm{Zn}$-air batteries. ${ }^{107}$

In the past decade, a combined experimental and theoretical strategy has been well developed to profoundly investigate the relationship among microstructure, catalytic mechanism and reaction kinetics of electrocatalysts. The theoretically urgent requirement is a more exact/effective descriptor to predict electrocatalytic activity or explain the reaction process. To achieve this goal, adequate kinetic conditions should be considered carefully and large computational power with more efficient computer codes are developed to treat the complexity. Moreover, it could be very helpful to establish a generally structured database containing simulated material properties, which can be shared by the researcher in the catalysis field. From the experimental point of view, difficulty in the clarification of the ORR mechanism and kinetics mainly remains in the following aspects: (i) exactly adjust the location/type, concentration and dispersion of dopants/defects in doped/defective carbon materials, (ii) advanced characterization of the dopants and defects, and (iii) directly detecting or investigating the chemical intermediates in the reaction process of electrocatalysis. Accordingly, new synthetic strategies must be developed to exactly adjust the dopants or defects in carbon catalysts. Bottom-up methods could be a powerful strategy to obtain precisely defined structure of heteroatom-doped carbon materials, just like the reported synthesis of atomically precise graphene nanostructure. ${ }^{108,109}$ Moreover, advanced characterization techniques should be extensively utilized to analyze the microstructure and composition of the carbon catalysts, such as, AC-HRTEM for microstructure, XAS for the local geometric or electronic structure, and electron spin resonance (ESR) for unpaired electrons. Importantly, in situ and operando spectroscopy/microscopy characterization, such as ambient pressure XPS (AP-XPS) and scanning electrochemical microscopy (SECM) also need to be developed to easily detect and quantify active sites. ${ }^{110,111}$ Time-resolved technique, such as ultrafast laser, is very powerful in detecting the molecular dynamics with the solution on the atomic scale. On the femtosecond time scale, the single-molecule trajectory can be observed through matter wave packets and their coherent evolution. ${ }^{112}$ Taking into account all these important aspects would make it possible to identify the active sites and make a real breakthrough in this exciting area.

\section{ACKNOWLEDGEMENTS}

The authors are grateful to the financial support from NSFC $(51602332,51502327)$, the National Key Research and Development Program of China (2016YFB0700204), Science and Technology Commission of Shanghai Municipality (15520720400, 16DZ2260603, 19ZR1479500), Equipment Research Program (6140721050215), and 100 Talent Plan of Chinese Academy of Sciences. M.Y. and G.S. would like to thank the National 1000 Youth Talents program of China. M.Y. thanks very much for financial support from Ningbo 3315 program.

\section{AUTHOR CONTRIBUTIONS}

R.M. and J.W. proposed the outline of the review. R.M. and G.L. wrote the manuscript. Q.L., T.Z., G.S., M.Y., and J.W. revised and commented on the manuscript.

\section{ADDITIONAL INFORMATION}

Competing interests: The authors declare no competing interests.
Publisher's note: Springer Nature remains neutral with regard to jurisdictional claims in published maps and institutional affiliations.

\section{REFERENCES}

1. Winter, M. \& Brodd, R. J. What are batteries, fuel cells, and supercapacitors? Chem. Rev. 104, 4245-4270 (2004).

2. Ioroi, T. et al. Electrocatalysts for PEM fuel cells. Adv. Energy Mater. 1801284 (2018).

3. Fu, J. et al. Electrically rechargeable zinc-air batteries: progress, challenges, and perspectives. Adv. Mater. 29, 1604685 (2017).

4. Li, Y. \& Dai, H. Recent advances in zinc-air batteries. Chem. Soc. Rev. 43 5257-5275 (2014)

5. Debe, M. K. Electrocatalyst approaches and challenges for automotive fuel cells. Nature 486, 43-51 (2012).

6. Gasteiger, H. A. et al. Activity benchmarks and requirements for Pt, Pt-alloy, and non-Pt oxygen reduction catalysts for PEMFCs. Appl. Catal. B 56, 9-35 (2005).

7. Guo, S. \& Sun, S. FePt Nanoparticles assembled on graphene as enhanced catalyst for oxygen reduction reaction. J. Am. Chem. Soc. 134, 2492-2495 (2012).

8. Jaouen, F. et al. Recent advances in non-precious metal catalysis for oxygenreduction reaction in polymer electrolyte fuel cells. Energy Environ. Sci. 4, 114-130 (2011).

9. Gong, K. et al. Nitrogen-doped carbon nanotube arrays with high electrocatalytic activity for oxygen reduction. Science 323, 760-764 (2009).

10. Zhang, J., Xia, Z. \& Dai, L. Carbon-based electrocatalysts for advanced energy conversion and storage. Sci. Adv. 1, e1500564 (2015).

11. Qu, L. et al. Nitrogen-doped graphene as efficient metal-free electrocatalyst for oxygen reduction in fuel cells. ACS Nano 4, 1321-1326 (2010).

12. Sheng, Z. H. et al. Catalyst-free synthesis of nitrogen-doped graphene via thermal annealing graphite oxide with melamine and its excellent electrocatalysis. ACS Nano 5, 4350-4358 (2011).

13. Yu, D., Zhang, Q. \& Dai, L. Highly efficient metal-free growth of nitrogen-doped single-walled carbon nanotubes on plasma-etched substrates for oxygen reduction. J. Am. Chem. Soc. 132, 15127-15129 (2010).

14. $\mathrm{Ma}$, R. et al. Novel synthesis of $\mathrm{N}$-doped graphene as an efficient electrocatalyst towards oxygen reduction. Nano Res. 9, 808-809 (2016).

15. Gu, D. et al. Facile synthesis of N-doped graphene-like carbon nanoflakes as efficient and stable electrocatalysts for the oxygen reduction reaction. Nano Micro Lett. 10, 29 (2017).

16. Yang, L. et al. Boron-doped carbon nanotubes as metal-free electrocatalysts for the oxygen reduction reaction. Angew. Chem. 123, 7270-7273 (2011).

17. Sheng, Z. H. et al. Synthesis of boron doped graphene for oxygen reduction reaction in fuel cells. J. Mater. Chem. 22, 390-395 (2012).

18. Yang, Z. et al. Sulfur-doped graphene as an efficient metal-free cathode catalyst for oxygen reduction. ACS Nano 6, 205-211 (2011).

19. Jeon, I. Y. et al. Edge-selectively sulfurized graphene nanoplatelets as efficient metal-free electrocatalysts for oxygen reduction reaction: the electron spin effect. Adv. Mater. 25, 6138-6145 (2013).

20. Wang, J. et al. Magnesiothermic synthesis of sulfur-doped graphene as an efficient metal-free electrocatalyst for oxygen reduction. Sci. Rep. 5, 9304 (2015).

21. $\mathrm{Ma}, \mathrm{Z}$. et al. Sulfur-doped graphene derived from cycled lithium-sulfur batteries as a metal-free electrocatalyst for the oxygen reduction reaction. Angew. Chem. Int. Ed. 54, 1888-1892 (2015).

22. Liu, Z. W. et al. Phosphorus-doped graphite layers with high electrocatalytic activity for the $\mathrm{O}_{2}$ reduction in an alkaline medium. Angew. Chem. Int. Ed. 50, 3257-3261 (2011)

23. Yao, Z. et al. Catalyst-free synthesis of iodine-doped graphenevia a facile thermal annealing process and its use for electrocatalytic oxygen reduction in an alkaline medium. Chem. Commun. 48, 1027-1029 (2012).

24. Jeon, I. Y. et al. Facile, scalable synthesis of edge-halogenated graphene nanoplatelets as efficient metal-free eletrocatalysts for oxygen reduction reaction. Sci. Rep. 3, 1810 (2013).

25. Yang, W. et al. Efficient metal-free oxygen reduction in alkaline medium on high-surface-area mesoporous nitrogen-doped carbons made from ionic liquids and nucleobases. J. Am. Chem. Soc. 133, 206-209 (2011).

26. Wang, $S$. et al. Vertically aligned BCN nanotubes as efficient metal-free electrocatalysts for the oxygen reduction reaction: a synergetic effect by Co-doping with Boron and Nitrogen. Angew. Chem. Int. Ed. 50, 11756-11760 (2011).

27. Wang, S. et al. BCN graphene as efficient metal-free electrocatalyst for the oxygen reduction reaction. Angew. Chem. Int. Ed. 51, 4209-4212 (2012).

28. Xue, Y. et al. Three-dimensional B,N-doped graphene foam as a metal-free catalyst for oxygen reduction reaction. Phys. Chem. Chem. Phys. 15, 12220-12226 (2013). 
29. Wang, X. et al. One-pot synthesis of nitrogen and sulfur co-doped graphene as efficient metal-free electrocatalysts for the oxygen reduction reaction. Chem. Commun. 50, 4839-4842 (2014).

30. $\mathrm{Xu}, \mathrm{J}$. et al. Sulfur and nitrogen co-doped, few-layered graphene oxide as a highly efficient electrocatalyst for the oxygen-reduction reaction. ChemSusChem 6, 493-499 (2013).

31. She, Y. et al. Facile Synthesis of nitrogen and sulfur codoped carbon from ionic liquid as metal-free catalyst for oxygen reduction reaction. ACS Appl. Mater. Interfaces 7, 7214-7221 (2015).

32. Choi, C. H. et al. B, N- and P, N-doped graphene as highly active catalysts for oxygen reduction reactions in acidic media. J. Mater. Chem. A 1, 3694-3699 (2013).

33. Ma, R. et al. lonic liquid-assisted synthesis of dual-doped graphene as efficient electrocatalysts for oxygen reduction. Carbon 102, 58-65 (2016).

34. Choi, C. H. et al. Binary and ternary doping of nitrogen, boron, and phosphorus into carbon for enhancing electrochemical oxygen reduction activity. ACS Nano 6, 7084-7091 (2012).

35. Sahraie, N. R. et al. Noble-metal-free electrocatalysts with enhanced ORR performance by task-specific functionalization of carbon using ionic liquid precursor systems. J. Am. Chem. Soc. 136, 14486-14497 (2014).

36. Dai, L. et al. Metal-free catalysts for oxygen reduction reaction. Chem. Rev. 115, 4823-4892 (2015).

37. Yang, S. et al. Efficient synthesis of heteroatom ( $\mathrm{N}$ or S)-doped graphene based on ultrathin graphene oxide-porous silica sheets for oxygen reduction reactions. Adv. Funct. Mater. 22, 3634-3640 (2012).

38. Zhang, L. et al. Catalytic Mechanisms of sulfur-doped graphene as efficient oxygen reduction reaction catalysts for fuel cells. J. Phys. Chem. C. 118, 3545-3553 (2014).

39. Jiang, Y. et al. Significant contribution of intrinsic carbon defects to oxygen reduction activity. ACS Catal. 5, 6707-6712 (2015).

40. Zhao, H. et al. Carbon for the oxygen reduction reaction: a defect mechanism. J. Mater. Chem. A 3, 11736-11739 (2015).

41. Cao, R. et al. Recent progress in non-precious catalysts for metal-air batteries. Adv. Energy Mater. 2, 816-829 (2012).

42. Wang, Z. L. et al. Oxygen electrocatalysts in metal-air batteries: from aqueous to nonaqueous electrolytes. Chem. Soc. Rev. 43, 7746-7786 (2014).

43. Liu, X. \& Dai, L. Carbon-based metal-free catalysts. Nat. Rev. Mater. 1, 16064 (2016).

44. Guo, D. et al. Active sites of nitrogen-doped carbon materials for oxygen reduction reaction clarified using model catalysts. Science 351, 361-365 (2016).

45. Nørskov, J. K. et al. Origin of the overpotential for oxygen reduction at a fuel-cell cathode. J. Phy. Chem. B 108, 17886-17892 (2004).

46. Rossmeisl, J. et al. Electrolysis of water on oxide surfaces. J. Electroanal. Chem. 607, 83-89 (2007).

47. Li, M. et al. N-doped graphene as catalysts for oxygen reduction and oxygen evolution reactions: theoretical considerations. J. Catal. 314, 66-72 (2014).

48. Ao, X. et al. Unraveling the high-activity nature of Fe-N-C electrocatalysts for oxygen reduction reaction: the extraordinary synergy between Fe-N4 and Fe4N. J. Mater. Chem. A 7, 11792-11801 (2019).

49. $\mathrm{Ge}, \mathrm{X}$. et al. Oxygen reduction in alkaline media: from mechanisms to recent advances of catalysts. ACS Catal. 5, 4643-4667 (2015).

50. Huang, Z.-F. et al. Design of efficient bifunctional oxygen reduction/evolution electrocatalyst: recent advances and perspectives. Adv. Energy Mater. 7, 1700544 (2017).

51. Hu, P. et al. Electrocatalytic activity of alkyne-functionalized AgAu alloy nanoparticles for oxygen reduction in alkaline media. Nanoscale 7, 9627-9636 (2015).

52. Szczesniak, D. et al. Energy band gaps in graphene nanoribbons with corners. EPL (Europhysics Letters) 114, 48001 (2016)

53. Niwa, $\mathrm{H}$. et al. X-ray absorption analysis of nitrogen contribution to oxygen reduction reaction in carbon alloy cathode catalysts for polymer electrolyte fuel cells. J. Power Sources 187, 93-97 (2009).

54. Kundu, S. et al. Electrocatalytic activity and stability of nitrogen-containing carbon Nanotubes in the oxygen reduction reaction. J. Phys. Chem. C. 113, 14302-14310 (2009).

55. Rao, C. V. et al. In search of the active site in nitrogen-doped carbon nanotube electrodes for the oxygen reduction reaction. J. Phys. Chem. Lett. 1, 2622-2627 (2010).

56. Parvez, K. et al. Nitrogen-doped graphene and its iron-based composite as efficient electrocatalysts for oxygen reduction reaction. ACS Nano 6, 9541-9550 (2012).

57. Liu, R. et al. Nitrogen-doped ordered mesoporous graphitic arrays with high electrocatalytic activity for oxygen reduction. Angew. Chem. Int. Ed. 49, 2565-2569 (2010).

58. Kim, $\mathrm{H}$. et al. On the mechanism of enhanced oxygen reduction reaction in nitrogen-doped graphene nanoribbons. Phys. Chem. Chem. Phys. 13, 17505-17510 (2011).
59. Lai, L. et al. Exploration of the active center structure of nitrogen-doped graphene-based catalysts for oxygen reduction reaction. Energy Environ. Sci. 5, 7936-7942 (2012).

60. Borghei, M. et al. High oxygen reduction activity of few-walled carbon nanotubes with low nitrogen content. Appl. Catal. B: Environ. 158-159, 233-241 (2014).

61. Zhao, A. et al. Activation and stabilization of nitrogen-doped carbon nanotubes as electrocatalysts in the oxygen reduction reaction at strongly alkaline conditions. J. Phys. Chem. C. 117, 24283-24291 (2013).

62. Vikkisk, M. et al. Enhanced electrocatalytic activity of nitrogen-doped multiwalled carbon nanotubes towards the oxygen reduction reaction in alkaline media. RSC Adv. 5, 59495-59505 (2015).

63. Chen, Z. et al. Highly Active Nitrogen-doped carbon nanotubes for oxygen reduction reaction in fuel cell applications. J. Phys. Chem. C. 113, 21008-21013 (2009).

64. Poh, H. L. et al. Sulfur-doped graphene via thermal exfoliation of graphite oxide in $\mathrm{H}_{2} \mathrm{~S}, \mathrm{SO}_{2}$, or $\mathrm{CS}_{2}$ Gas. ACS Nano 7, 5262-5272 (2013).

65. Zhang, $C$. et al. Synthesis of phosphorus-doped graphene and its multifunctional applications for oxygen reduction reaction and lithium ion batteries. Adv. Mater. 25, 4932-4937 (2013).

66. Yang, D. S. et al. Highly efficient metal-free phosphorus-doped platelet ordered mesoporous carbon for electrocatalytic oxygen reduction. Carbon 67, 736-743 (2014).

67. Ishizaki, T. et al. Effects of halogen doping on nanocarbon catalysts synthesized by a solution plasma process for the oxygen reduction reaction. Phys. Chem. Chem. Phys. 18, 21843-21851 (2016).

68. $\mathrm{Wu}, \mathrm{K} . \mathrm{H}$. et al. Solution phase synthesis of halogenated graphene and the electrocatalytic activity for oxygen reduction reaction. Chin. J. Catal. 35, 884-890 (2014).

69. Sun, X. et al. Fluorine-doped carbon blacks: highly efficient metal-free electrocatalysts for oxygen reduction reaction. ACS Catal. 3, 1726-1729 (2013).

70. Zheng, Y. et al. Two-step boron and nitrogen doping in graphene for enhanced synergistic catalysis. Angew. Chem. Int. Ed. 52, 3110-3116 (2013).

71. Liang, J. et al. Sulfur and nitrogen dual-doped mesoporous graphene electrocatalyst for oxygen reduction with synergistically enhanced performance. Angew. Chem. Int. Ed. 51, 11496-11500 (2012).

72. You, J. M. et al. New approach of nitrogen and sulfur-doped graphene synthesis using dipyrrolemethane and their electrocatalytic activity for oxygen reduction in alkaline media. J. Power Sources 275, 73-79 (2015).

73. Hu, C. \& Dai, L. Multifunctional carbon-based metal-free electrocatalysts for simultaneous oxygen reduction, oxygen evolution, and hydrogen evolution. Adv. Mater. 29, 1604942 (2017).

74. Silva, R., Voiry, D., Chhowalla, M. \& Asefa, T. Efficient metal-free electrocatalysts for oxygen reduction: polyaniline-derived $\mathrm{N}$ - and O-doped mesoporous carbons. J. Am. Chem. Soc. 135, 7823-7826 (2013).

75. Razmjooei, F. et al. Enhanced electrocatalytic activity due to additional phosphorous doping in nitrogen and sulfur-doped graphene: a comprehensive study. Carbon 78, 257-267 (2014).

76. Lin, $\mathrm{H}$. et al. Boron, nitrogen, and phosphorous ternary doped graphene aerogel with hierarchically porous structures as highly efficient electrocatalysts for oxygen reduction reaction. New J. Chem. 40, 6022-6029 (2016).

77. Li, J. S. et al. Heteroatoms ternary-doped porous carbons derived from MOFs as metal-free electrocatalysts for oxygen reduction reaction. Sci. Rep. 4, 5130 (2014).

78. Qu, K., Zheng, Y., Dai, S. \& Qiao, S. Z. Graphene oxide-polydopamine derived N, S-codoped carbon nanosheets as superior bifunctional electrocatalysts for oxygen reduction and evolution. Nano Energy 19, 373-381 (2016).

79. Pei, Z. et al. Texturing in situ: N,S-enriched hierarchically porous carbon as a highly active reversible oxygen electrocatalyst. Energy Environ. Sci. 10, 742-749 (2017).

80. Nørskov, J. K. et al. Density functional theory in surface chemistry and catalysis. Proc. Natl Acad. Sci. USA 108, 937-943 (2011).

81. Exner, K. S. \& Over, H. Kinetics of Electrocatalytic Reactions from First-Principles: a critical comparison with the Ab initio thermodynamics approach. Acc. Chem. Res. 50, 1240-1247 (2017).

82. Hammer, B. \& Norskov, J. K. Why gold is the noblest of all the metals. Nature 376, 238 (1995).

83. Suntivich, J. et al. Design principles for oxygen-reduction activity on perovskite oxide catalysts for fuel cells and metal-air batteries. Nat. Chem. 3, 546 (2011).

84. Zhang, L. \& Xia, Z. Mechanisms of oxygen reduction reaction on nitrogen-doped graphene for fuel cells. J. Phys. Chem. C. 115, 11170-11176 (2011).

85. Zhang, $X$. et al. The mechanisms of oxygen reduction reaction on phosphorus doped graphene: a first-principles study. J. Power Sources 276, 222-229 (2015). 
86. $\mathrm{Wu}, \mathrm{K} . \mathrm{H}$. et al. A discussion on the activity origin in metal-free nitrogen-doped carbons for oxygen reduction reaction and their mechanisms. ChemSusChem $\mathbf{8}$, 2772-2788 (2015).

87. $\mathrm{Yu}, \mathrm{L}$. et al. Oxygen reduction reaction mechanism on nitrogen-doped graphene: a density functional theory study. J. Catal. 282, 183-190 (2011).

88. Chai, G. L. et al. Active sites and mechanisms for oxygen reduction reaction on nitrogen-doped carbon alloy catalysts: Stone-Wales defect and curvature effect. J. Am. Chem. Soc. 136, 13629-13640 (2014).

89. Fazio, G., Ferrighi, L. \& Di Valentin, C. Boron-doped graphene as active electrocatalyst for oxygen reduction reaction at a fuel-cell cathode. J. Catal. 318, 203-210 (2014)

90. Flyagina, I. S. et al. A theoretical study of molecular oxygen chemisorption on $\mathrm{N}$, B, or O doped carbon edge sites. Fuel Cells 14, 709-719 (2014).

91. del Cueto, M., Ocón, P. \& Poyato, J. M. L. Comparative study of oxygen reduction reaction mechanism on nitrogen-, phosphorus-, and boron-doped graphene surfaces for fuel cell applications. J. Phys. Chem. C. 119, 2004-2009 (2015).

92. Jiao, Y. et al. Origin of the electrocatalytic oxygen reduction activity of graphene-based catalysts: a roadmap to achieve the best performance. J. Am. Chem. Soc. 136, 4394-4403 (2014).

93. Zhao, Z. et al. Design principles for heteroatom-doped carbon nanomaterials as highly efficient catalysts for fuel cells and metal-air batteries. Adv. Mater. 27, 6834-6840 (2015).

94. Li, F. et al. Electrocatalytic activity and design principles of heteroatom-doped graphene catalysts for oxygen-reduction reaction. J. Phys. Chem. C. 121, 14434-14442 (2017).

95. Deng, D. et al. Size effect of graphene on electrocatalytic activation of oxygen. Chem. Commun. 47, 10016-10018 (2011).

96. Jeon, I. Y. et al. Large-scale production of edge-selectively functionalized graphene nanoplatelets via ball milling and their use as metal-free electrocatalysts for oxygen reduction reaction. J. Am. Chem. Soc. 135, 1386-1393 (2013).

97. Shen, A. et al. Oxygen reduction reaction in a droplet on graphite: direct evidence that the edge is more active than the basal plane. Angew. Chem. 126, 10980-10984 (2014).

98. Jin, H. et al. Graphene quantum dots supported by graphene nanoribbons with ultrahigh electrocatalytic performance for oxygen reduction. J. Am. Chem. Soc. 137, 7588-7591 (2015).

99. Tang, C. et al. Topological defects in metal-free nanocarbon for oxygen electrocatalysis. Adv. Mater. 28, 6845-6851 (2016).

100. Zhao, X. et al. Defect-driven oxygen reduction reaction (ORR) of carbon without any element doping. Inorg. Chem. Front. 3, 417-421 (2016).

101. He, W.-T. et al. Renewable Porous carbons prepared by $\mathrm{KOH}$ activation as oxygen reduction Electrocatalysts. J. Inorg. Mater. https://doi.org/10.15541/ jim20190036 (2019).
102. Yan, X. et al. Activated carbon becomes active for oxygen reduction and hydrogen evolution reactions. Chem. Commun. 52, 8156-8159 (2016).

103. Jia, Y. et al. Defect graphene as a trifunctional catalyst for electrochemical reactions. Adv. Mater. 28, 9532-9538 (2016).

104. Jia, Y. et al. The role of defect sites in nanomaterials for electrocatalytic energy conversion. Chem 5, 1371-1397 (2019).

105. Xing, R. et al. Creation of triple hierarchical micro-meso-macroporous N-doped carbon shells with hollow cores toward the electrocatalytic oxygen reduction reaction. Nano Micro Lett. 10, 3 (2017).

106. Lin, G. et al. $\mathrm{KOH}$ activation of biomass-derived nitrogen-doped carbons for supercapacitor and electrocatalytic oxygen reduction. Electrochim. Acta 261, 49-57 (2018).

107. Wang, Q. et al. Pyridinic-N-dominated doped defective graphene as a superior oxygen electrocatalyst for ultrahigh-energy-density Zn-air batteries. ACS Energy Lett. 3, 1183-1191 (2018).

108. Cai, J. et al. Graphene nanoribbon heterojunctions. Nat. Nanotech. 9, 896 (2014).

109. Dössel, L. et al. Graphene nanoribbons by chemists: nanometer-sized, soluble, and defect-free. Angew. Chem. Int. Ed. 50, 2540-2543 (2011).

110. Malko, D. et al. In situ electrochemical quantification of active sites in Fe-N/C non-precious metal catalysts. Nat. Commun. 7, 13285 (2016).

111. Kim, J. et al. Electrocatalytic activity of individual Pt nanoparticles studied by nanoscale scanning electrochemical microscopy. J. Am. Chem. Soc 138, 8560-8568 (2016)

112. Zewail, A. H. Femtochemistry: atomic-scale dynamics of the chemical bond using ultrafast lasers (Nobel Lecture). Angew. Chem. Int. Ed. 39, 2586-2631 (2000).

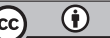

Open Access This article is licensed under a Creative Commons Attribution 4.0 International License, which permits use, sharing, adaptation, distribution and reproduction in any medium or format, as long as you give appropriate credit to the original author(s) and the source, provide a link to the Creative Commons license, and indicate if changes were made. The images or other third party material in this article are included in the article's Creative Commons license, unless indicated otherwise in a credit line to the material. If material is not included in the article's Creative Commons license and your intended use is not permitted by statutory regulation or exceeds the permitted use, you will need to obtain permission directly from the copyright holder. To view a copy of this license, visit http://creativecommons. org/licenses/by/4.0/.

(c) The Author(s) 2019 